\title{
A Survey on FOPID Controllers for LFO Damping in Power Systems Using Synchronous Generators, FACTS Devices and Inverter-Based Power Plants
}

\author{
Mahdi Saadatmand ${ }^{1}(\mathbb{D})$, Gevork B. Gharehpetian ${ }^{2}\left(\mathbb{D}\right.$, Innocent Kamwa ${ }^{3}$ (D) Pierluigi Siano ${ }^{4,5, *(D)}$, \\ Josep M. Guerrero ${ }^{6}$ iD and Hassan Haes Alhelou ${ }^{7,8, *}$ \\ 1 Power System Secure Operation Research Center, Amirkabir University of Technology, \\ Tehran 159163-4311, Iran; m.saadatmand@aut.ac.ir \\ 2 Department of Electrical Engineering, Amirkabir University of Technology, Tehran 159163-4311, Iran; \\ grptian@aut.ac.ir \\ 3 Hydro-Québec/IREQ, Power System and Mathematics, Varennes, QC J3X 1S1, Canada; \\ Innocent.kamwa.1@ulaval.ca \\ 4 Department of Management \& Innovation Systems, University of Salerno, 84084 Fisciano, Italy \\ 5 Department of Electrical and Electronic Engineering Science, University of Johannesburg, \\ Johannesburg 2006, South Africa \\ 6 Center for Research on Microgrids (CROM), Department of Energy Technology, Aalborg University, \\ 9220 Aalborg, Denmark; joz@et.aau.dk \\ 7 School of Electrical and Electronic Engineering, University College Dublin, D04 V1W8 Dublin, Ireland \\ 8 Department of Electrical Power Engineering, Tishreen University, 2230 Lattakia, Syria \\ * Correspondence: psiano@unisa.it (P.S.); Hassan.haesalhelou@ucd.ie (H.H.A.)
}

Citation: Saadatmand, M.;

Gharehpetian, G.B.; Kamwa, I.; Siano,

P.; Guerrero, J.M.; Haes Alhelou, H. A

Survey on FOPID Controllers for LFO

Damping in Power Systems Using

Synchronous Generators, FACTS

Devices and Inverter-Based Power

Plants. Energies 2021, 14, 5983.

https://doi.org/10.3390/en14185983

Academic Editor: Abu-Siada Ahmed

Received: 10 August 2021

Accepted: 16 September 2021

Published: 21 September 2021

Publisher's Note: MDPI stays neutral with regard to jurisdictional claims in published maps and institutional affiliations.

Copyright: (c) 2021 by the authors. Licensee MDPI, Basel, Switzerland. This article is an open access article distributed under the terms and conditions of the Creative Commons Attribution (CC BY) license (https:// creativecommons.org/licenses/by/ $4.0 /)$
Abstract: In recent decades, various types of control techniques have been proposed for use in power systems. Among them, the use of a proportional-integral-derivative (PID) controller is widely recognized as an effective technique. The generalized type of this controller is the fractional-order PID (FOPID) controller. This type of controller provides a wider range of stability area due to the fractional orders of integrals and derivatives. These types of controllers have been significantly considered as a new approach in power engineering that can enhance the operation and stability of power systems. This paper represents a comprehensive overview of the FOPID controller and its applications in modern power systems for enhancing low-frequency oscillation (LFO) damping. In addition, the performance of this type of controller has been evaluated in a benchmark test system. It can be a driver for the development of FOPID controller applications in modern power systems. Investigation of different pieces of research shows that FOPID controllers, as robust controllers, can play an efficient role in modern power systems.

Keywords: fractional-order proportional-integral-derivative (FOPID) controller; FACTS; inverterbased power plant (IBPP); low-frequency oscillation (LFO); power oscillation damping controller (PODC); synchronous generator (SG)

\section{Introduction}

With the development of power systems in the world, as well as the existence of new types of applications, the concept of power system stability is becoming very important. Accordingly, one of the most important issues is the robustness of power systems against uncertainties [1,2]. A robust controller is a controller that has a wide stability area and where the system uncertainties do not affect its performance significantly. So, in recent years, many studies on robust controllers have been conducted by researchers around the world [3]. On the other hand, one of the important problems of power grids is the risk of low-frequency oscillation (LFO) [4]. LFO is an electro-mechanical phenomenon that occurs in power systems due to the lack of damping torque [1-4]. The common technique for damping LFOs is to use an auxiliary controller called a power system stabilizer (PSS) in an 
automatic voltage regulator (AVR) of a synchronous generator (SG) [1-4]. Conventional PSSs are the lead-lag compensators (LLCs) that are easy to design [5]. The operating mechanism of these types of controllers is based on the injection of an additional voltage signal into the excitation system of an SG. The input of these controllers can be the deviation of the frequency, power or variation of the generator rotor angle $[1,2,6]$.

Recently, many studies have been conducted on LFO damping by power system devices, such as flexible AC transmission system (FACTS) devices, [5] and [7-10], and inverter-based power plants (IBPPs) [11-18]. Studies have been performed with various types of control strategies and electrical controllers. In the studies, the proposed controllers have been used as power oscillation damping controllers (PODCs). One of these types of controllers is the fractional-order proportional-integral-derivative (FOPID) controller [19-25]. Conventional PODCs, although easy to set up and install, with industrial applications, have many problems and challenges. For example, LLCs [15] and proportional-integral-derivative (PID) controllers [18] have a small stability area. Another important issue is the robustness of the PODCs against power system uncertainties. Therefore, it is necessary that a PODC, in addition to the abilities of easy tuning and being applicable for industrialization, has a wide range of stability as well as sufficient robustness against power system uncertainties.

Due to the robustness and wide stability area of the FOPID controller, its application in power systems has been widely discussed in many studies. Most of the studies of FOPID controller applications in power systems have been related to load frequency control (LFC) [26-29] and automatic generation control (AGC) [30-34]. Additionally, in [35] the FOPID controller was used to improve the power quality. In many studies, the FOPID controller has been investigated as a PODC to mitigate LFOs by SGs [36-44], FACTS devices $[45,46]$, and IBPPs [47-49]. Given the advantages of the FOPID controller, it is expected that these types of controllers will be used extensively for LFO damping in modern power systems.

The aim of this paper is to introduce FOPID controllers and investigate the advantages and challenges of their application for LFO damping in modern power systems. For this purpose, an overview of the power system stability has been done with a focus on LFO. The fractional-order calculus is then presented in order to provide the model of the FOPID controller that can be used for LFO damping in modern power systems. Furthermore, this paper represents the optimization techniques used to tune the FOPID controller parameters in order to achieve better performance for LFO damping. In addition, a comparison has been made between the performance of FOPID controllers and other proposed controllers to damp LFOs in power systems. For this purpose, a benchmark test system has been used and the necessary simulations have been performed in different operating conditions. Additionally, this study highlights the opportunities and challenges of using FOPID controllers with the aim of introducing future research topics.

The rest of the paper is organized as follows. Section 2 provides an overview of the LFOs. An overview of fractional-order calculus, the role of FOPID controller to increase the stability area, and the structure of FOPID controller are introduced in Section 3. Then, Section 4 describes the tuning methods of FOPID controllers. The applications of FOPID controllers for LFO damping are presented in Section 5. Moreover, the PODC performance evaluation and comparative simulations are presented in Section 6. Then, opportunities and challenges are provided in Section 7. Section 8 provides the discussion, while Section 9 concludes.

\section{Concept of LFOs}

LFOs are one of the most important factors in destroying power system stability. The system's ability to maintain the acceptable point of operation during and after disturbances is called power system stability $[1,2,50]$. This concept is classified into main categories as shown in Figure 1 [50-52]. One of the categories is rotor angle stability, which is defined as the capability of SGs to maintain or restore the balance between mechanical torque 
and electromagnetic torque [2]. Based on the power system events, rotor angle stability is classified into two different categories as follows:

- Small-signal stability;

- Transient stability.

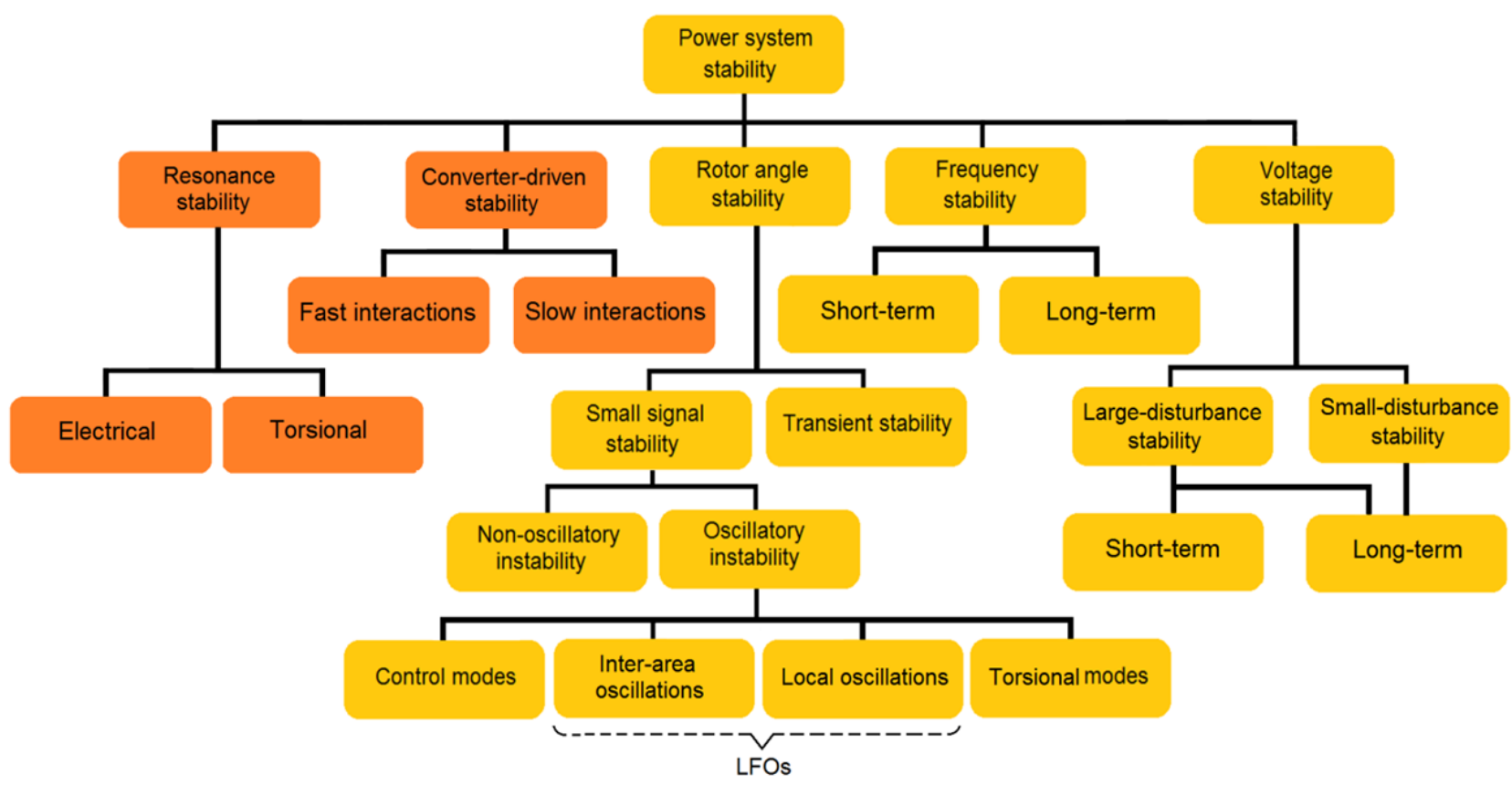

Figure 1. Power system stability classification.

The small-signal stability analysis is classified into two various categories: an oscillatory condition due to lack of damping torque and a non-oscillatory condition due to lack of synchronizing torque [4]. In oscillatory conditions, oscillation with a frequency between $0.1 \mathrm{~Hz}$ to $2 \mathrm{~Hz}$ is called LFO [2,3], which is divided into two general categories as follows [2,3]:

- Oscillation with a frequency between $0.1 \mathrm{~Hz}$ to $1 \mathrm{~Hz}$, due to the oscillation in a group of SGs or power plants in an area relative to SGs or power plants in another area, called inter-area oscillation [2,3];

- Oscillation with a frequency between $1 \mathrm{~Hz}$ to $2 \mathrm{~Hz}$, due to the oscillation in an SG or a power plant relative to an SG or power plant in the same area, called local oscillation $[2,3]$.

In conventional power systems, LFOs are usually damped by the PSS of SGs. It should be noted that although LFOs are the most important section of oscillatory states, control modes and torsional modes are also in the category of oscillatory states.

\section{Review of the FOPID Controller}

The mathematical model of this type of controller is based on fractional-order calculus [53-56]. This type of calculus is the general form of integer-order calculus. Although fractional-order calculus is very old, its use in the design of controllers is limited to recent years [53-56].

\subsection{Concept of Fractional-Order Calculus}

Fractional-order calculus is a basic concept in mathematics that actually expands the conventional integer-order calculus to the desired orders. The history of this concept dates back to about 300 years ago. However, due to the complexities of this concept, its implementation has been studied in recent decades. This is while there is still no physical and tangible understanding of fractional-order calculus [19]. 
The fundamental form of the fractional-order differentiator, which can be represented by a general operator as a general form of differential and integral operators, is defined as follows, extracted from [19] and [53-55]:

$$
{ }_{a} D_{t}^{q}=\left\{\begin{array}{c}
\frac{d^{q}}{d t^{q}}, q>0 \\
1, q=0 \\
\int_{a}^{t}(d \tau)^{-q}, q<0
\end{array}\right.
$$

where, $q, a$, and $t$ denote the fractional-order and lower as well as upper limits of the operator $D$, respectively. Generally, there are three different definitions for the fractionalorder differentiator [53-55]:

- The Grunwald-Letnikov (GL) definition;

- The Riemann-Liouville (RL) definition;

- The Caputo dinition.

The GL definition is as follows:

$$
\begin{gathered}
{ }_{a} D_{t}^{q} f(t)=\lim _{h \rightarrow 0} \frac{1}{h^{q}} \sum_{j=0}^{[(t-a) / h]}(-1)^{j}\left(\begin{array}{c}
n \\
j
\end{array}\right) f(t-j h) \\
\left(\begin{array}{c}
n \\
j
\end{array}\right)=\frac{\Gamma(n+1)}{\Gamma(j+1) \Gamma(n-j+1)} .
\end{gathered}
$$

where $n$ is the integer value that satisfies the condition and $n-1<q<n$. Furthermore, operator [ ] in (2) indicates a floor function [53-55]. Moreover, $\Gamma$ function notes Euler's gamma function as follows [53-55]:

$$
\Gamma(x)=\int_{0}^{\infty} t(x-1) e^{-t} d t
$$

In addition, the RL definition is as follows [53-55]:

$$
{ }_{a} D_{t}^{q} f(t)=\frac{1}{\Gamma(n-q)} \frac{d^{n}}{d t^{n}} \int_{a}^{t} \frac{f(\tau)}{(t-\tau)^{q-n+1}} d \tau
$$

Additionally, the Caputo definition is as follows [53-55]:

$$
{ }_{a} D_{t}^{q} f(t)=\frac{1}{\Gamma(n-q)} \int_{a}^{t} \frac{f^{n}(\tau)}{(t-\tau)^{q-n+1}} d \tau
$$

\subsection{Stability of Fractional-Order System}

Execution of the fractional-order controller in a power system changes the mathematical model of the system from integer-order to fractional-order. Fractional-order linear time-invariant (FOLTI) dynamic systems are modeled by a differential equation as follows $[19,53]$ :

$$
a_{a_{n}} D^{q_{n}} y(t)+{ }_{a_{n-1}} D^{q_{n-1}} y(t)+\cdots+{ }_{a_{0}} D^{q_{0}} y(t)={ }_{b_{m}} D^{r_{m}} y(t)+{ }_{b_{m-1}} D^{r_{m-1}} y(t)+\cdots+{ }_{b_{0}} D^{r_{0}} y(t)
$$

where $D^{x} \equiv{ }_{0} D_{t}^{x}$ defines the RL derivative, $a_{k}, b_{l}$ for $k=0, \ldots, n$ and $l=0, \ldots, m$ are constants, and $q_{k}, r_{l}$ for $k=0, \ldots, n$ and $l=0, \ldots, m$ are arbitrary real numbers. Moreover, 
$q_{n}>q_{n-1}>\cdots>q_{0}$ and $r_{n}>r_{n-1}>\cdots>r_{0}$. The transfer function of a FOLTI system with incommensurate orders is as follows $[19,53]$ :

$$
C(s)=\frac{b_{m} s^{r_{m}}+b_{m-1} s^{r_{m-1}}+\cdots+b_{0} s^{r_{0}}}{a_{n} s^{q_{n}}+a_{n-1} s^{q_{n-1}}+\cdots+a_{0} s^{q_{0}}}=\frac{Y\left(s^{r_{k}}\right)}{R\left(s^{q_{k}}\right)}
$$

Additionally, for a fractional-order system with commensurate-order $q$, it holds that $q_{k}=q k, r_{k}=q k,(0<q<1) \forall k \in Z$. This system is as follows $[19,53]$ :

$$
C(s)=K_{0} \frac{\sum_{k=0}^{M} b_{k}\left(s^{q}\right)^{k}}{\sum_{k=0}^{N} a_{k}\left(s^{q}\right)^{k}}=K_{0} \frac{Y\left(s^{q}\right)}{R\left(s^{q}\right)}
$$

The stability condition for this system is presented as below $[19,53]$ :

Matignon's Stability Theorem. A fractional-order system with commensurate-order $q$, explained by a rational transfer function shown in (9) is stable if and only if, $\left|\arg \left(\lambda_{i}\right)\right|>q(\pi / 2)$ for all $i$, where $\lambda_{i}$ is the ith root of $R\left(s^{q}\right)$.

The state-space model of FOLTI systems is stated as below [19,53]:

$$
\begin{gathered}
{ }_{0} D_{h}^{q} x(t)=A x(t)+B u(t) \\
y(t)=C x(t)
\end{gathered}
$$

where $x \in R^{n}, u \in R^{m}$, and $y \in R^{p} R^{\mathrm{p}}$ are the state vector, vector of system inputs, and vector of system outputs. For an nth-order system with $\mathrm{m}$ inputs and p outputs, $A \in R^{n \times n}$, $B \in R^{n \times m}$, and $C \in R^{p \times n}$ are the system matrix, input matrix, and output matrix. Moreover, $q=\left[q_{1}, q_{2}, \ldots, q_{n}\right]^{T}$ is the fractional-order vector. The fractional-order system in (10) and (11) is stable if and only if:

$$
|\arg (\operatorname{eig}(A))|>(q \pi) / 2
$$

where $\operatorname{eig}(A)$ denotes the eigenvalue of the system matrix. As shown in Figure 2, the fractional-order system's stability range depends on the value of fractional-order $q$. Therefore, changing the value of $q$ can increase or decrease the stability range [19,53]. As shown in this figure, the maximum stability range of the fractional-order system is in the case where the $q$ is between 0 and 1 .

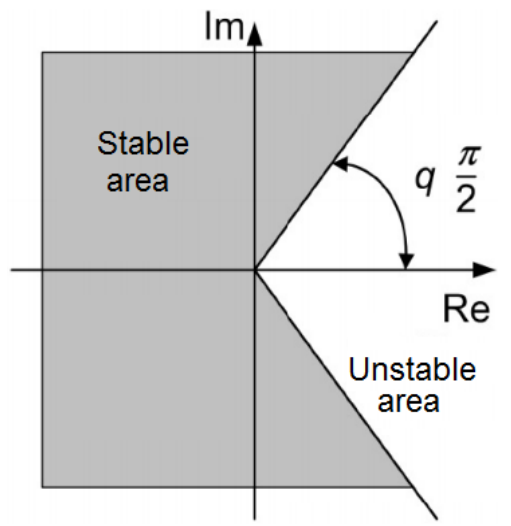

(A)

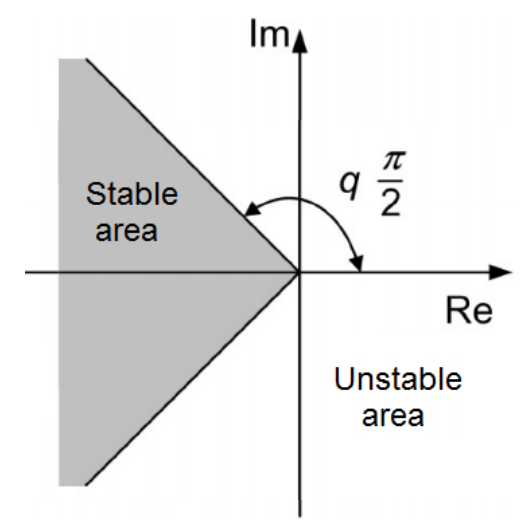

(B)

Figure 2. Stability area of the fractional-order system for the various values of $q$ : (A) $0<q<1$; (B) $1<q<2$. 


\subsection{FOPID Controller}

The FOPID controller is actually an extended form of the PID controller. Since the PID controller has derivative and integral operators, the FOPID controller has a fractional order between 0 and 1 for each operator. According to the contents of the previous section, it can be concluded that the FOPID controller has a higher range of stability compared to the PID controller due to extra degrees of freedom resulting from the order of fractional integral $\lambda$ and the order of fractional derivative $\delta$, extracted from [19] and [53-56].

High flexibility in design and robustness against system uncertainties, especially in non-linear systems, are the most important advantages of the FOPID controller $[19,53,56]$. The fractional differential equation of this type of controller is as follows [20-27]:

$$
U(t)=K_{P} E(t)+K_{I} D_{t}^{-\lambda} E(t)+K_{D} D_{t}^{\delta} E(t)
$$

Additionally, to model this type of controller, it is necessary to obtain its transfer function in the Laplace domain. The transfer function $C(s)$ in the Laplace domain is expressed as follows:

$$
C(s)=\frac{U(s)}{E(s)}=K_{P}+K_{I} s^{-\lambda}+K_{D} s^{\delta}
$$

where $E(s), U(s), K_{P}, K_{I}$, and $K_{D}$ present the system input, system output, proportional gain, integral gain, and derivative gain of the FOPID controller, respectively. Moreover, $\lambda$ and $\delta$ display the fractional orders of integrals and derivatives. The block diagram of the FOPID controller has been shown in Figure 3A [20-27]. As depicted in Figure 3B, the FOPID controller extends the PID controller from a point to a plane [20].

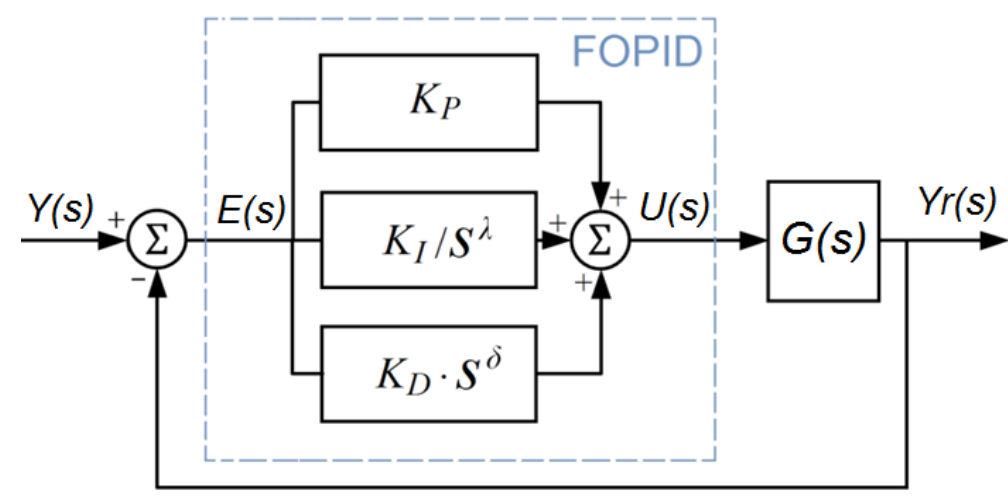

(A)

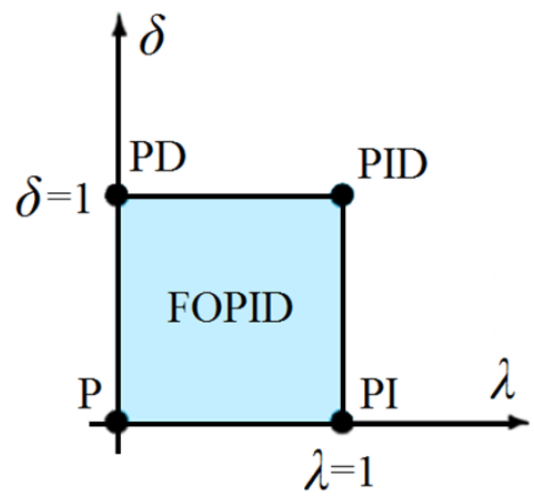

(B)

Figure 3. The FOPID controller: (A) structure in a control loop; (B) graphical presentation in $\delta-\lambda$ plane.

\section{Tuning Methods of FOPID Controllers}

Although the controller is very flexible in design, it is not easy to design and it is challenging. The FOPID controller design determines three gains and two fractional orders. The fractional-order parameters in the differential equation of the FOPID controller and the large number of parameters makes it impossible to use popular methods for controller design [56]. According to [20,55], design methods can be classified into three various categories, as follows:

- Rule-based techniques;

- Numerical techniques;

- Analytical techniques.

Two techniques have been applied for FOPID controller design in various studies for power system applications. The rule-based technique is based on approximation $[42,56,57]$, and the numerical technique is based on optimization [58,59]. The first technique is based 
on the approximation of the fractional-order function to an integer-order function $[43,57]$. Additionally, the numerical technique is to use optimization algorithms to determine the optimal values of the parameters [39-45,58,59]. This technique has been used in the literature for the application of the FOPID controller as a PODC, so this will be stated in detail in the next section.

It should be noted that the analytical techniques are based on the specified optimal behavior of the system, so the aim is to minimize the steady-state error. The analytical techniques are based on the Nyquist method. However, other methods may also be used to design fractional-order controllers in the future. Although FOPID controller design with different methods has many complexities and challenges, however, controller design using optimization methods is simpler than rule-based and analytical methods and has a wide variety of optimization algorithms. Moreover, the analytical method is very complex and has so far been used less in power system applications. However, analytical methods are very accurate in controller design and are widely used in theoretical studies of control systems.

\section{Optimization Methods Technique}

In this technique, the parameters of the FOPID controller are determined by solving an optimization problem subjected to technical constraints [20,59-61]. As indicated in Figure 3 and based on Equation (14), the closed-loop transfer function is as follows [19]:

$$
\frac{Y(s)}{Y_{r}(s)}=\frac{C(s) G(s)}{1+C(s) G(s)}
$$

where $Y(s)$ and $Y_{r}(s)$ are the input and output of the closed-loop system. Therefore, the steady-state error of the closed-loop system is [19]:

$$
E(s)=Y(s)-Y_{r}(s)=\frac{C(s) G(s)}{1+C(s) G(s)} Y_{r}(s)-Y_{r}(s)
$$

where there are five unknown parameters in the FOPID controller. Therefore, the objective function $J$ is defined as follows $[20,60]$ :

$$
J\left(K_{P}, K_{I}, K_{D}, \lambda, \delta\right)
$$

As shown in Equation (17), there are many parameters for optimal adjustment of the FOPID controller; therefore, the controller tuning is a challenging task [39-49]. The optimization process has been depicted in Figure 4.

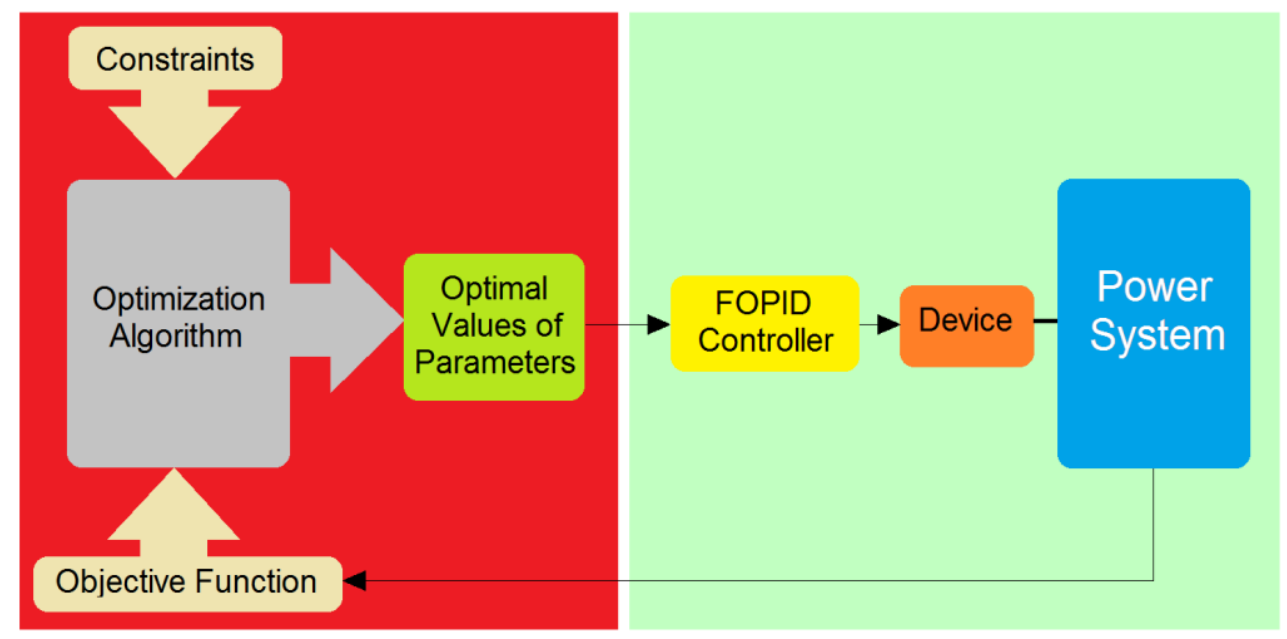

Figure 4. Optimization process for FOPID controller design. 
The optimization process is to determine the optimal values of controller parameters based on a specific objective; therefore, it is necessary to define a proper objective function. Many popular objective functions have been defined and used based on $E(s)$ minimization, such as follows [39-44]:

$$
\begin{aligned}
& J_{1}=\int_{0}^{\infty}(e(t))^{2} d t \\
& J_{2}=\int_{0}^{\infty} t(e(t))^{2} d t \\
& J_{3}=\int_{0}^{\infty}|e(t)| d t \\
& J_{4}=\int_{0}^{\infty} t|e(t)| d t
\end{aligned}
$$

where $e(t)$ is the steady-state error. Furthermore, $J_{1}, J_{2}, J_{3}$, and $J_{4}$ demonstrate the integral squared error (ISE), integral of the time-weighted squared error (ITSE), integral absolute error (IAE), and integral time-weighted absolute error (ITAE) indices, respectively [40-42,60,62]. In [47-49], the ITAE index has been used as a non-linear objective function for time-domain simulation. Likewise, the ITSE index has been used as an objective function in [45]. Table 1 shows the optimization algorithms used to tune the FOPID controller in power systems.

Table 1. Literature of FOPID controller design using optimization algorithms for power system applications.

\begin{tabular}{ccc}
\hline Reference & Optimization Algorithm & Power System Application \\
\hline$[32]$ & Teaching-learning-based optimization (TLBO) & AGC \\
{$[36]$} & Particle swarm optimization (PSO) & PODC \\
{$[37,38]$} & Chaotic non-dominated sorting genetic algorithm-II (chaotic NSGA-II) & PODC \\
{$[39]$} & Genetic algorithm (GA), ant colony optimization (ACO) & PODC \\
{$[40]$} & Bat algorithm (BA) & PODC \\
{$[41]$} & Cuckoo search (CS) & PODC \\
{$[42]$} & Sine-cosine algorithm (SCA) & PODC \\
{$[43]$} & Hybrid firefly algorithm-PSO (FAPSO) & PODC \\
{$[44]$} & Chaotic yellow saddle goatfish algorithm & PODC \\
{$[45]$} & Improved PSO (IPSO) & PODC \\
{$[46]$} & Dolphin echolocation optimization (DEO) & PODC \\
{$[47]$} & PSO & PODC \\
{$[48]$} & PSO, GA & PODC \\
{$[49]$} & TLBO, PSO, GA & PODC \\
{$[63]$} & SCA & AGC \\
{$[64]$} & Chaotic multi-objective optimization & LFC \\
{$[66]$} & Atom search optimization (ASO) & LFC \\
{$[67]$} & Chaotic ASO (ChASO) & Controller of DC motor \\
{$[68]$} & Bacterial foraging optimization algorithm (BFOA), hybrid firefly & AGC
\end{tabular}

\section{FOPID Controller for LFO Damping in Power Systems}

As mentioned, many studies have focused on the LLC, PID, linear quadratic Gaussian (LQG), FOPID, and other controllers for damping the LFOs in power systems. In this section, the FOPID controllers implemented in power system equipment to damp LFOs are reviewed and discussed.

\subsection{FOID-PODC of SG}

A PSS is an auxiliary controller connected to the exciter of an SG to damp LFOs. Research on new advanced control methods to improve PSS performance is a very interesting topic in electrical engineering. For this purpose, many types of control methods, including 
adaptive control [70-72], gain-scheduling fuzzy control [73], robust control [74], and sliding mode control [75] have been carried out in the last two decades to improve the performance of PSSs. A robust and flexible control approach whose potential is now being examined in various engineering applications is based on FOPID controllers [19-21]. Usually, the PSS of an SG is the conventional LLC [2]. The first idea to use the FOPID controller as a PODC was to use it instead of PSS in the exciter of an SG, as depicted in Figure 5 [36].

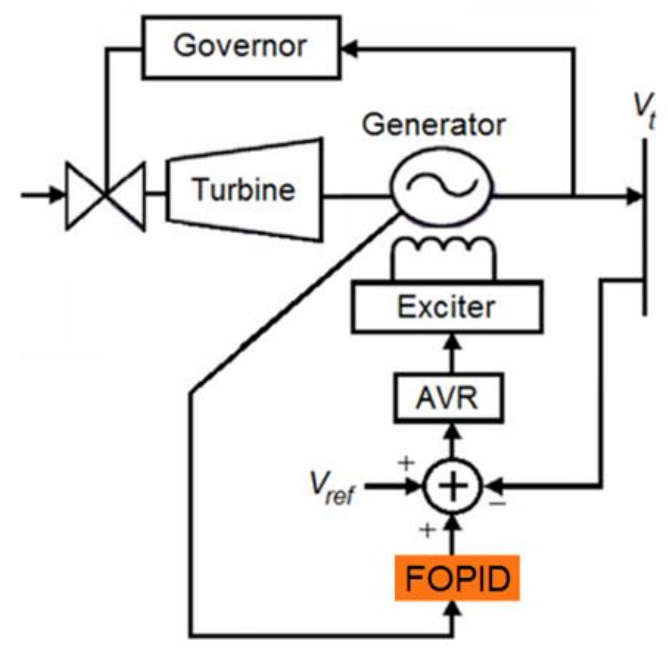

Figure 5. The simple structure of the SG control system with the FOPID controller.

In [36-44], the FOPID controller has been proposed as a PODC of the AVR system. The results of the studies indicated the better performance of the FOPID controller than the PID controller and conventional LLC for LFO damping and dynamic stability improvement due to its flatness in the phase margin contribution with a wider bandwidth. Furthermore, simulation results indicated that the FOPID controller provides better robustness performance than the PID and conventional LLC under power system uncertainties and disturbance conditions [36-45].

In [36], the usage of the FOPID controller in an AVR has been studied. In the paper, the PSO algorithm has been used for FOPID controller tuning. In the study, a new objective function, considered to facilitate the control mode over both the time-domain and the frequency-domain specifications, was examined. The simulation results showed that the FOPID controller can highly improve the system robustness with respect to model uncertainties. In other studies in 2012 [37] and 2013 [38], the FOPID controller was designed as a PODC for an AVR system. In the studies, an improved evolutionary NSGA, expanded with a chaotic map, has been used for controller tuning. Additionally, the multi-objective function has been defined for optimization.

In [38], the controller tuning has been done in the frequency domain, so stability and robustness have been automatically guaranteed, unlike the other time-domain optimizationbased tuning techniques. Additionally, another study in 2016 [39] proposed a FOPID controller for implementation in the excitation system of an SG. The study used the GA and ACO optimizations for controller tuning.

In 2017 [40], the FOPID controller tuning was done using a meta-heuristic optimization, BA. This optimization algorithm is based on the echolocation behavior for power system stability improvement. Furthermore, the problem of FOPID controller tuning has been solved based on the optimization method using performance indices, including IAE, ISE, ITAE, and ITSE. The simulation results illustrated that the FOPID controller provides better performance than conventional PID controller and LLC. In another study in 2018 [41], a robust FOPID controller was proposed for the excitation system of an SG as a PODC. In the study, the FOPID controller has been tuned using the CS algorithm. Then, the system performance was evaluated. The simulation results showed the better performance of the 
CS-based FOPID controller than the PSO-based FOPID controller and the PID controller. Additionally, in [42] the FOPID controller was suggested as a PODC and adjusted by an advanced SCA optimization method. Moreover, the time-domain objective function has been considered for optimization. The results of the research indicated the proper performance of the FOPID controller in terms of frequency responses, reference tracking, and LFO damping. In 2019 [43], the implementation of a hybrid FAPSO algorithm for optimizing the parameters of a FOPID controller was suggested. In the research, the FOPID controller was designed by considering speed deviation and acceleration as input signals. The results demonstrated that the FOPID controller provides better performance in terms of LFO damping compared to the conventional PSSs. Additionally, the results showed the better performance of the hybrid FAPSO algorithm than other optimization algorithms such as PSO, hybrid GA, and bacterial foraging optimization in terms of optimal tuning of the FOPID controller. Furthermore, in other study in 2020 [44], the FOPID controller was proposed for an AVR system as a PSS application. In the study, the SCA and chaotic yellow saddle goatfish algorithm were used for controller designs.

\subsection{FOPID-PODC of FACTS Devices}

Due to the development of FACTS devices application in power systems, applying the FACTS-based PODCs is an efficient method to damp the LFOs [3]. One of the important types of these devices is the thyristor-controlled series capacitor (TCSC). This device has been proposed in many studies as a series compensator [76-78]. The internal structure of a TCSC is illustrated in Figure 6.

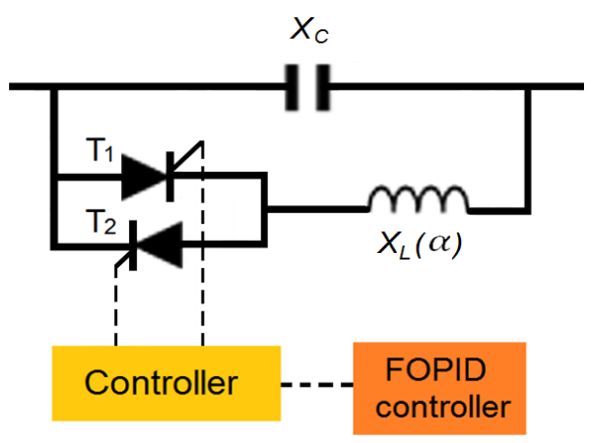

Figure 6. Schematic of a TCSC with the FOPID controller.

In the TCSC the capacitive impedance, $X_{C}$, is constant and the amount of reactance, $X_{L}(\alpha)$, is adjusted by the firing angle of the thyristors. Accordingly, the impedance of the TCSC is as follows [10,79]:

$$
X_{T C S C}(\alpha)=\frac{X_{C} X_{L}(\alpha)}{X_{L}(\alpha)-X_{C}}
$$

As shown in (22), the TCSC impedance is a function of the thyristors' firing angle. In [45], the FOPID controller has been used as a PODC in the TCSC for LFO damping and improve the rotor angle stability. Additionally, the FOPID-PODC has been coordinated with an AGC loop. The TCSC dynamic model with the FOPID controller has been shown in Figure 7.

Parameters of the FOPID controller and AGC loop have been optimally tuned using an IPSO algorithm. Furthermore, the ITSE index has been used as an objective function. The simulation results showed the better dynamic performance of the FOPID controller than conventional PODCs in terms of reducing the risk of LFOs. Moreover, the investigation of the results showed that with the addition of the fractional-order controller, the power system is strongly robust to the system uncertainties and severe disturbances. 


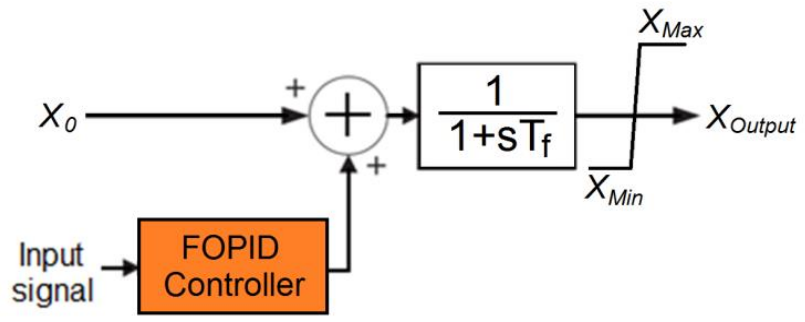

Figure 7. Dynamic model of a TCSC with the FOPID controller.

Additionally, in another study in 2018 [46], the FOPID controller was proposed to mitigate the LFOs and stabilize the dynamic behavior of the power system using a static synchronous compensator (STATCOM). In the paper, the DEO algorithm was used and its superiority compared to other optimization algorithms for FOPID controller tuning was shown.

\subsection{FOPID-PODC of IBPPS}

Climate change and the tendency to use clean energy have increased the influence of IBPPs in the world. Due to the fact that these types of power plants don't have rotating components, their high penetration level reduces the power system's inertia $[80,81]$. Accordingly, many studies have raised the subject of LFO damping by these types of power plants [11-17]. This is done by considering the various control strategies or designing different controllers, such as conventional LLCs [12,14], PID controllers [17], and LQG controllers [11].

In 2020 [47] the use of the FOPID controller in the dynamic model of an IBPP as a PODC was suggested. In the research, an LPF was considered as a case study. In addition, the controller was tuned using PSO. Furthermore, in the research, the objective function has been considered based on the ITAE index. The results indicated the better performance of the FOPID controller for LFO damping than the PID controller, LQG controller, and conventional LLCs. It should be noted that, as depicted in Figure 8, the generic dynamic model of IBPP includes three sub-models as below [82]:

- The renewable energy generator/converter (REGC);

- The renewable energy electrical control (REEC);

- The renewable energy plant control (REPC).

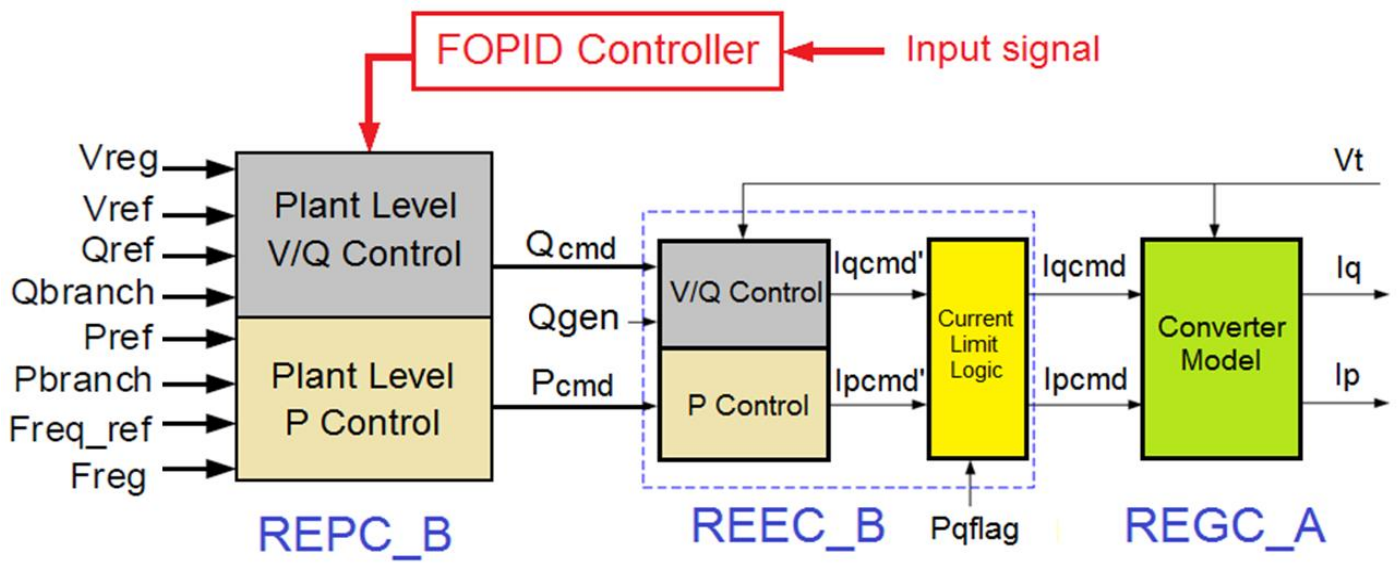

Figure 8. General structure of the dynamic model of an LPF with the FOPID controller.

The proposed FOPID controller in the study has been connected to the REPC.

In 2021 [48], a method was suggested for coordinated tuning of the FOPID controller of an LPF and PSSs of SGs in order to damp the LFOs. Recently, in a study [49], a phasor measurement unit (PMU)-based FOPID controller was proposed to mitigate LFOs via 
a large-scale hybrid wind-PV farm (LWPF). In the study, the performance of the LWPF for LFO damping by the FOPID controller was evaluated. The robustness of the FOPID controller against some uncertainties of the power system was also investigated. As shown in Figure 9, the papers suggested two different positions for the PODC in the REPC. The results of the studies show the proper performance and robustness of the FOPID controller compared to the popular controllers in a wide range of disturbances and uncertainties.
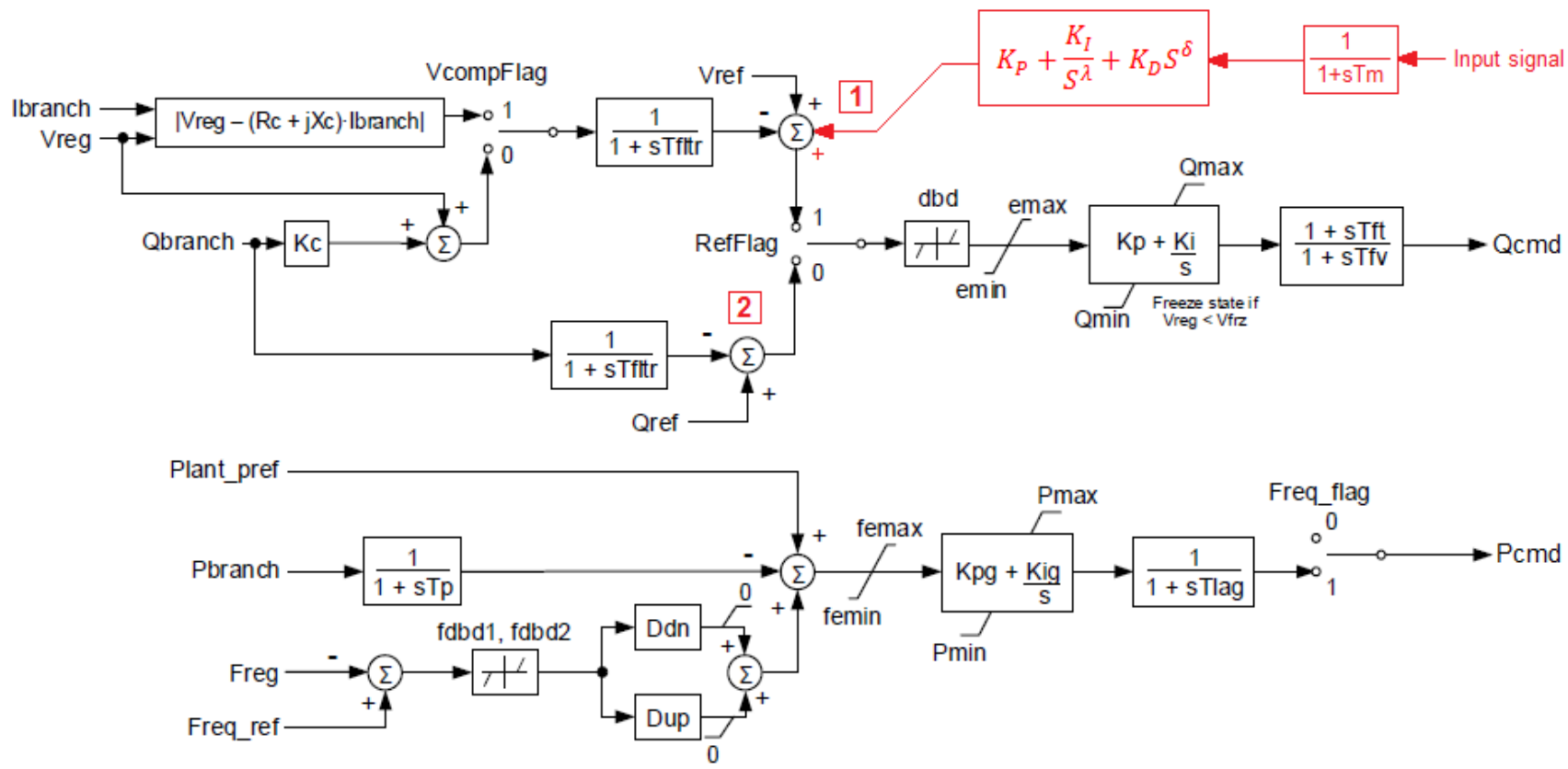

Figure 9. Block diagram of an REPC_B module of an LPF dynamic model with the FOPID controller.

The results of the studies show that the FOPID controller is suitably capable of being used as a PODC. Table 2 summarizes the literature.

Table 2. Summary of the FOPID controller for LFO mitigation in power systems.

\begin{tabular}{|c|c|c|c|c|c|}
\hline Reference & Device & Tuning Method & $\begin{array}{l}\text { Comparison } \\
\text { with Other } \\
\text { Controllers }\end{array}$ & $\begin{array}{l}\text { Time- } \\
\text { Domain } \\
\text { Analysis }\end{array}$ & $\begin{array}{l}\text { Frequency- } \\
\text { Domain } \\
\text { Analysis }\end{array}$ \\
\hline [36] & SG & Optimization by PSO & No & Yes & No \\
\hline$[37,38]$ & SG & $\begin{array}{c}\text { Optimization by chaotic } \\
\text { NSGA-II }\end{array}$ & No & Yes & No \\
\hline [39] & SG & Optimization by ACO & Yes & Yes & No \\
\hline$[40]$ & SG & Optimization by BA & Yes & Yes & No \\
\hline [41] & SG & Optimization by CS & Yes & Yes & No \\
\hline [42] & SG & Optimization by SCA & Yes & Yes & No \\
\hline [43] & SG & Optimization by FAPSO & No & Yes & Yes \\
\hline$[44]$ & SG & $\begin{array}{l}\text { Optimization by chaoticyellow } \\
\text { saddle goatfish algorithm }\end{array}$ & No & Yes & No \\
\hline [45] & FACTS (TCSC) & Optimization by IPSO & Yes & Yes & Yes \\
\hline [46] & FACTS (STATCOM) & Optimization by DEO & No & Yes & No \\
\hline [47] & IBPP (LPF) & Optimization by PSO & Yes & Yes & No \\
\hline [48] & IBPP (LPF) & Optimization by PSO & Yes & Yes & No \\
\hline [49] & IBPP (LWPF) & Optimization by TLBO & Yes & Yes & No \\
\hline
\end{tabular}




\section{Performance Evaluation and Comparative Simulation}

The performance of the FOPID-PODC in comparison to other proposed PODCs has been examined in this section. Therefore, a modified two-area system has been used in this paper $[2,83]$. For this purpose, three different scenarios are considered as shown in Table 3. These scenarios include different applications of the FOPID controller to mitigate the LFOs in the benchmark test system.

Table 3. Three scenarios for the FOPID controller in a power system as a PODC, based on the literature.

\begin{tabular}{cc}
\hline Scenario & Application \\
\hline 1 & Supplementary controller for excitation system of an SG as a PSS \\
2 & Auxiliary controller of TCSC as a PODC \\
3 & Supplementary controller of LPF controller as a PODC \\
\hline
\end{tabular}

The modified system according to the scenarios is shown in Figure 10. Moreover, the specifications of the system are listed in Table 4 . It should be noted that other data is in accordance with [2]. The benchmark test system is a smart grid under a wide-area measurement system (WAMS). In this system, the required signals are measured by PMUs and sent to the phasor data concentrator (PDC) for data processing. Furthermore, command signals are sent to the desired devices. Note that signal transmission has a time delay that should be applied in research and simulations. Although the time delay is a random value, in this study the signal transmission time delay between PMUs, PDCs, and PODCs is considered as a constant time delay, Tm, which is $100 \mathrm{~ms}$ as shown in Table 4 [47-49].

Table 4. Characteristics of the benchmark system.

\begin{tabular}{cc}
\hline Item & Description/Value \\
\hline Dynamic model of SGs & Sixth-order model \\
Exciters model & IEEE-ST1A \\
PSSs model & STAB1 \\
Loads & Constant power load \\
Constant time delay of signal transmission & $100 \mathrm{~ms}[84,85]$ \\
\hline
\end{tabular}

Simulation is required for assessing the performance of the suggested PODCs in the reviewed applications. Therefore, four states are considered as follows:

- State 1: A three-phase fault at bus 8 at $t=1 \mathrm{~s}$ for $170 \mathrm{~ms}$.

- State 2: Disconnection of line $L 12$ at $t=1 \mathrm{~s}$ for $67 \mathrm{~ms}$.

- State 3: Disconnection of generator $G 1$ at $t=1 \mathrm{~s}$ for $67 \mathrm{~ms}$.

- State 4: Disconnection of load 2 at $t=1 \mathrm{~s}$ for $67 \mathrm{~ms}$.

It should be noted that the values of the FOPID-PODC parameters, $K_{P}, K_{I}, K_{D}, \lambda, \delta$, in the three scenarios are obtained using the PSO algorithm. Furthermore, the ITAE index has been used as an objective function. In addition, the error function was defined as follows [62,86]:

$$
|e(t)|=\sum_{G=1}^{n_{G}}\left|\Delta \omega_{G}(t)\right|
$$

where $n_{G}$ and $\Delta \omega_{G}$ denote the number of SGs and speed deviation of generator $G$, respectively. In order to obtain the value of the ITAE, it is necessary to consider a severe disturbance in the test system. In this study, a three-phase short circuit at bus 8 for $100 \mathrm{~ms}$ is considered as a severe disturbance. For this purpose, (21) must be minimized subject to parameter constraints. The constraints of the FOPID-PODC parameters are indicated in Table 5 [86]. 


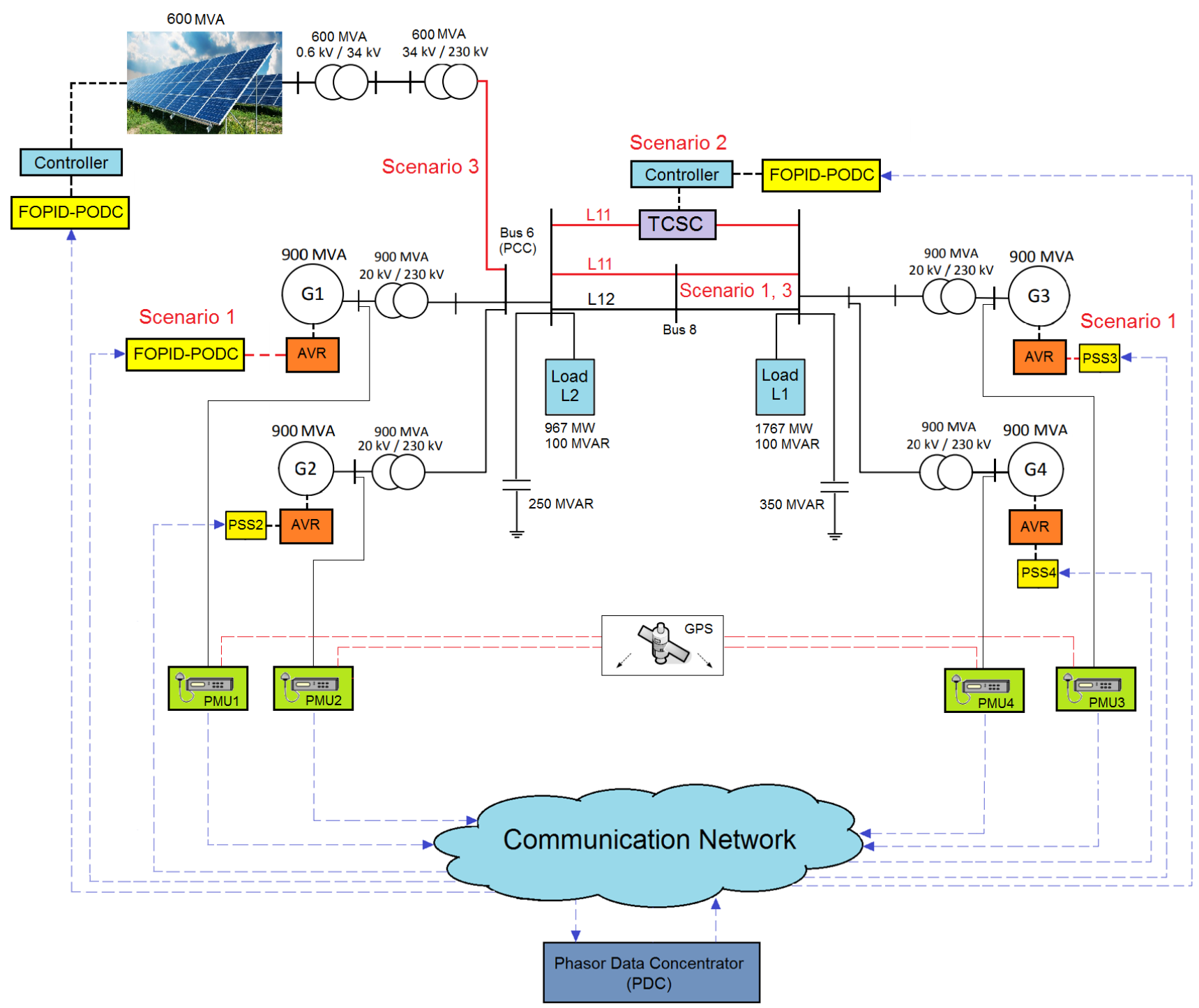

Figure 10. Benchmark test system for three scenarios.

Table 5. Constraints of the FOPID-PODC parameters.

\begin{tabular}{cccccc}
\hline Item & $\boldsymbol{K}_{\boldsymbol{P}}$ & $\boldsymbol{K}_{\boldsymbol{I}}$ & $\boldsymbol{K}_{\boldsymbol{D}}$ & $\boldsymbol{\lambda}$ & $\boldsymbol{\delta}$ \\
\hline Upper range & 100 & 100 & 100 & 1 & 1 \\
Lower range & 0 & 0 & 0 & 0 & 0 \\
\hline
\end{tabular}

\subsection{Scenario 1}

In this scenario, the excitation system of generator G2 is equipped with a FOPID-PODC as depicted in Figure 10. Additionally, other generators were equipped with conventional PSSs. It should be noted that, other system specifications are in accordance with [2]. The optimal values of the PODC parameters are available in Table 6. 
Table 6. Optimal values of the FOPID-PODC parameters for scenario 1.

\begin{tabular}{cc}
\hline Item & Value \\
\hline$K_{P}$ & 32.752 \\
$K_{I}$ & 64.958 \\
$K_{D}$ & 82.003 \\
$\lambda$ & 0.4910 \\
$\delta$ & 0.5360 \\
\hline
\end{tabular}

Note that the FOPID controller with the optimal set of parameters can mitigate both inter-area and local oscillations. This is exactly the same as the PSS mechanism. In fact, all types of PODCs can damp both types of oscillations. Of course, the most effective is the use of a multi-band PODC.

The simulation results performed in four states are presented in Figures 11 and 12. It should be noted that the simulation is based on a comparison between the performance of the FOPID controller and other proposed PODCs in the literature [87-98].
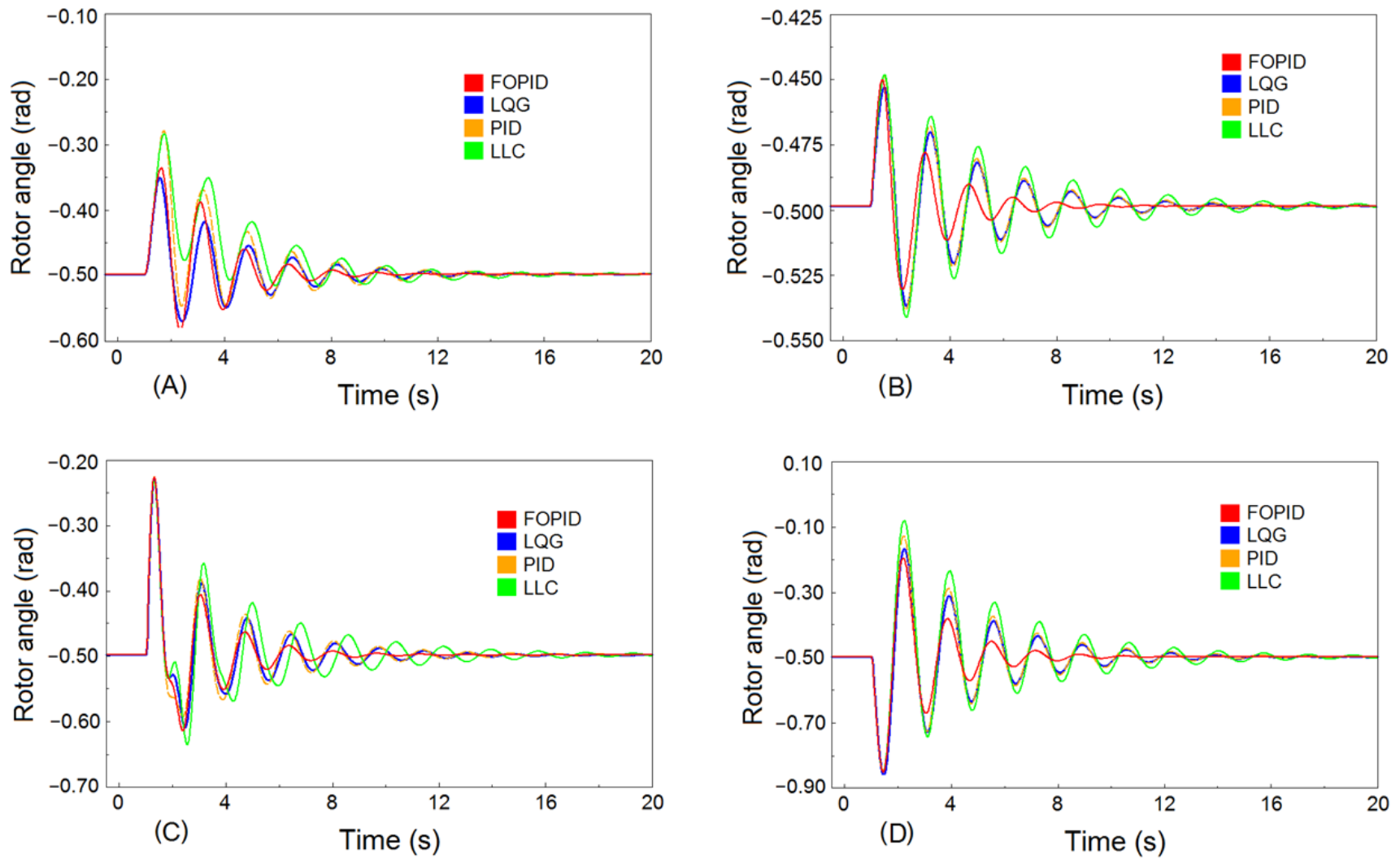

Figure 11. Rotor angle of generator G1 for scenario 1: (A) state 1, (B) state 2, (C) state 3, and (D) state 4.

Based on the simulation results, the FOPID-PODC performs well compared to the literature. Based on (21), the ITAE index has been used to compare the performance of the FOPID-PODC with the literature. As indicated in Figure 13, the value of the ITAE index for the FOPID-PODC is lower than the other controllers in the four scenarios. This indicates the proper performance of the FOPID-PODC in terms of LFO damping. 

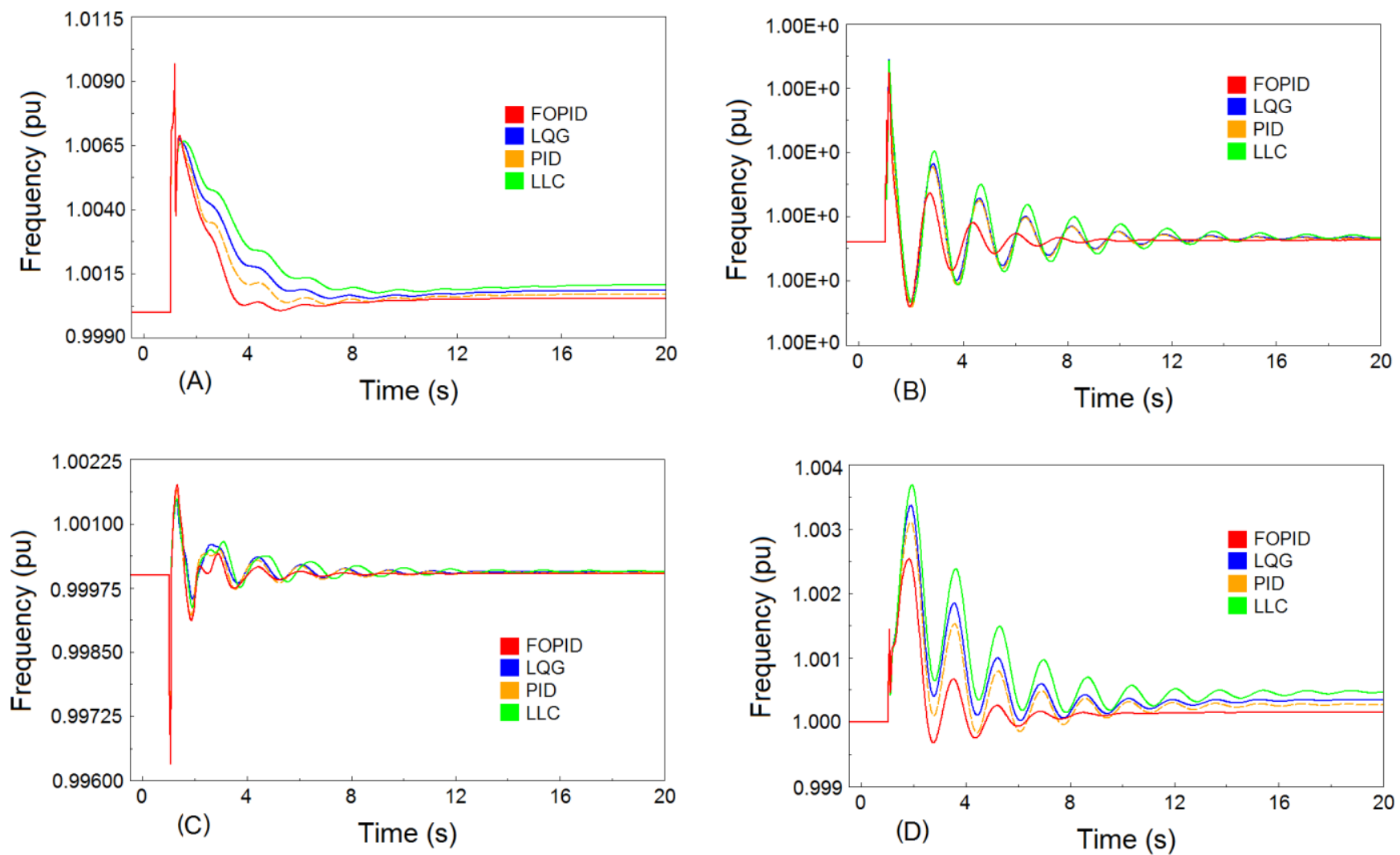

Figure 12. Power system frequency at bus 6 for scenario 1: (A) state 1, (B) state 2, (C) state 3, and (D) state 4.

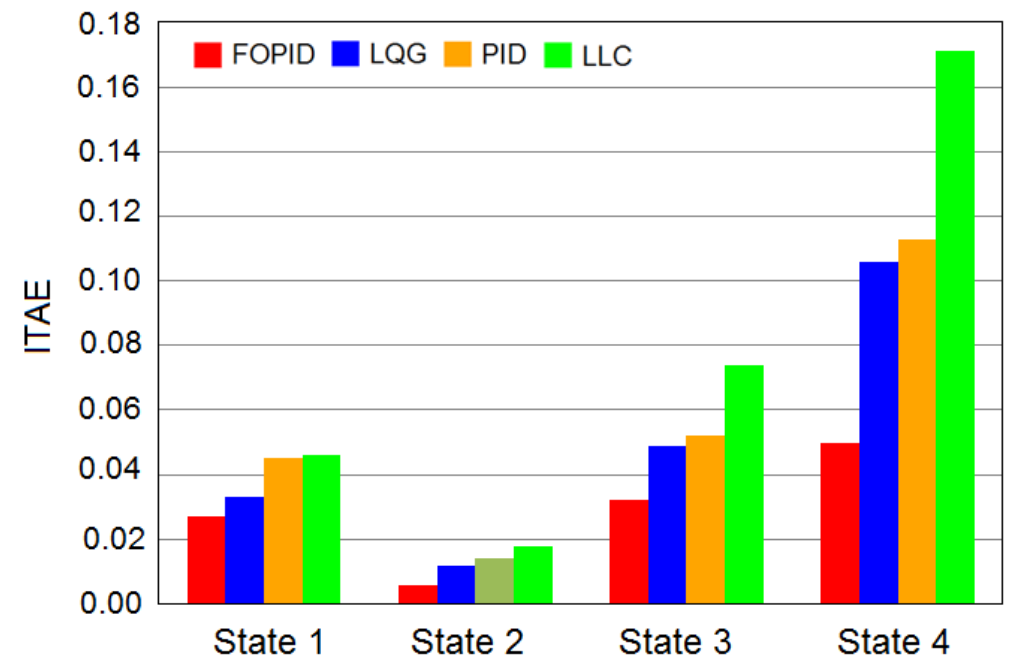

Figure 13. ITAE index for scenario 1.

\subsection{Scenario 2}

In this section, the compensation scenario of transmission line L11, which is actually the main line between the two areas in the test system, is presented as depicted in Figure 10. The specifications of the benchmark test system are in accordance with [2], except that the TCSC has been added to line L11. Moreover, only generators G2 and G4 have the PSSs as shown in Figure 11. The TCSC is equipped with the FOPID controller as a PODC. The values of the TCSC parameters for simulation are listed in Table 7 [85]. 
Table 7. TCSC parameters.

\begin{tabular}{cc}
\hline Parameter & Value \\
\hline Time constant of TCSC $\left(T_{f}\right)(\mathrm{s})$ & 0.05 \\
Series capacitor of TCSC $(X c)(\mathrm{Ohm})$ & 20 \\
$X_{\text {L-Min }}($ minimum reactance) $(\mathrm{Ohm})$ & 25 \\
$X_{\text {L-Max }}($ maximum reactance) $(\mathrm{Ohm})$ & 50 \\
$X_{\text {Min }}(\mathrm{Ohm})$ & 11.1 \\
$X_{\text {Max }}(\mathrm{Ohm})$ & 14.3 \\
\hline
\end{tabular}

Based on Equations (21) and (22), the optimal values of the FOPID-PODC parameters are defined by the PSO algorithm. The results are shown in Table 8.

Table 8. Optimal values of the FOPID-PODC parameters for Scenario 2.

\begin{tabular}{cc}
\hline Item & Value \\
\hline$K_{P}$ & 86.423 \\
$K_{I}$ & 61.622 \\
$K_{D}$ & 73.355 \\
$\lambda$ & 0.687 \\
$\delta$ & 0.337 \\
\hline
\end{tabular}

For performance evaluation of the proposed PODC, it is necessary to compare the controller with the literature $[5,9,99-104]$. Therefore, the necessary simulations are performed for four types of controllers: the FOPID controller, LLCs, the PID controller, and the LQG controller. The simulation results are illustrated in Figures 14 and 15. Furthermore, the ITAE index for each controller is obtained in four states as shown in Figure 16.
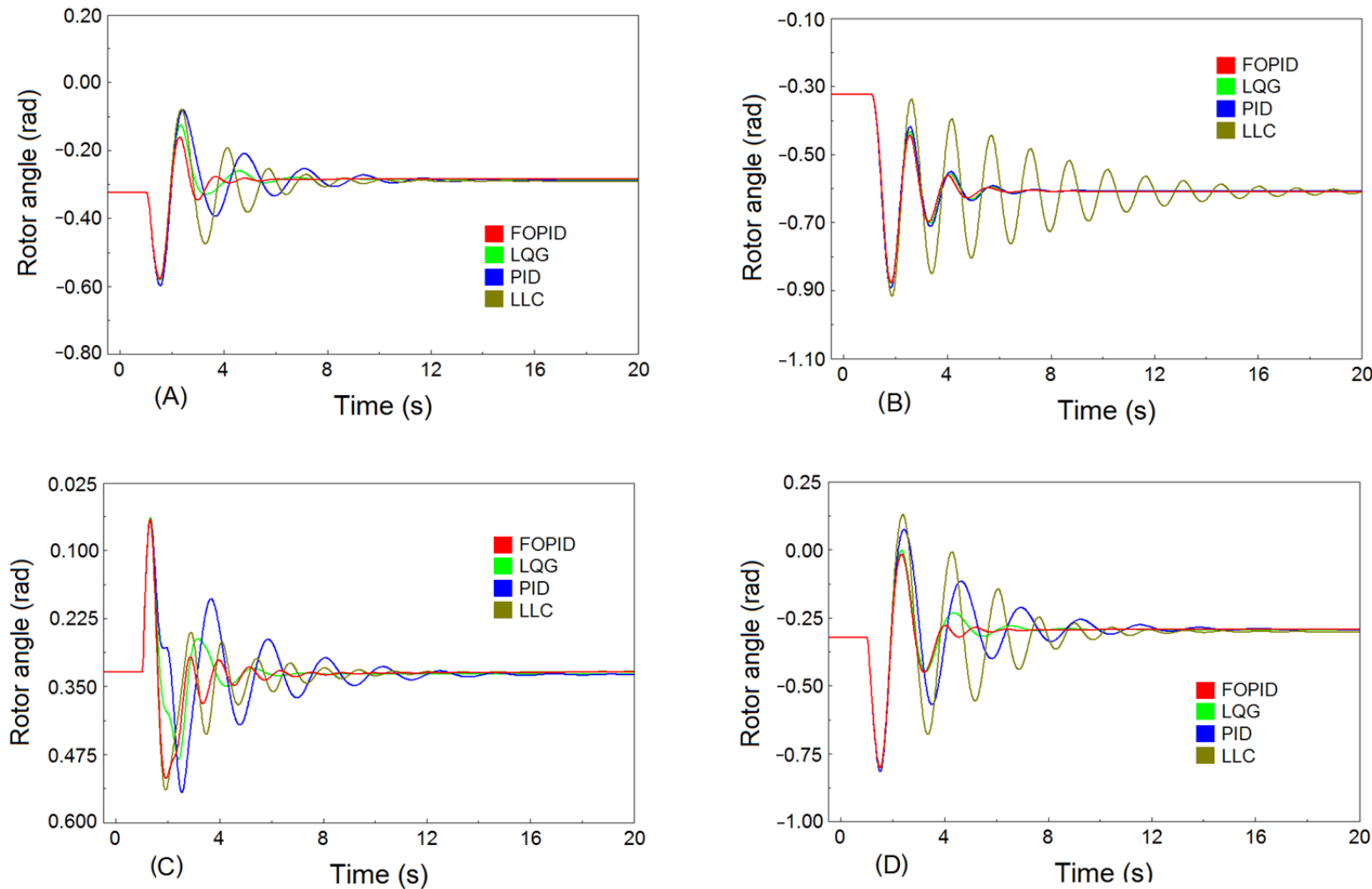

Figure 14. Rotor angle of generator G1 for scenario 2: (A) state 1, (B) state 2, (C) state 3, and (D) state 4. 

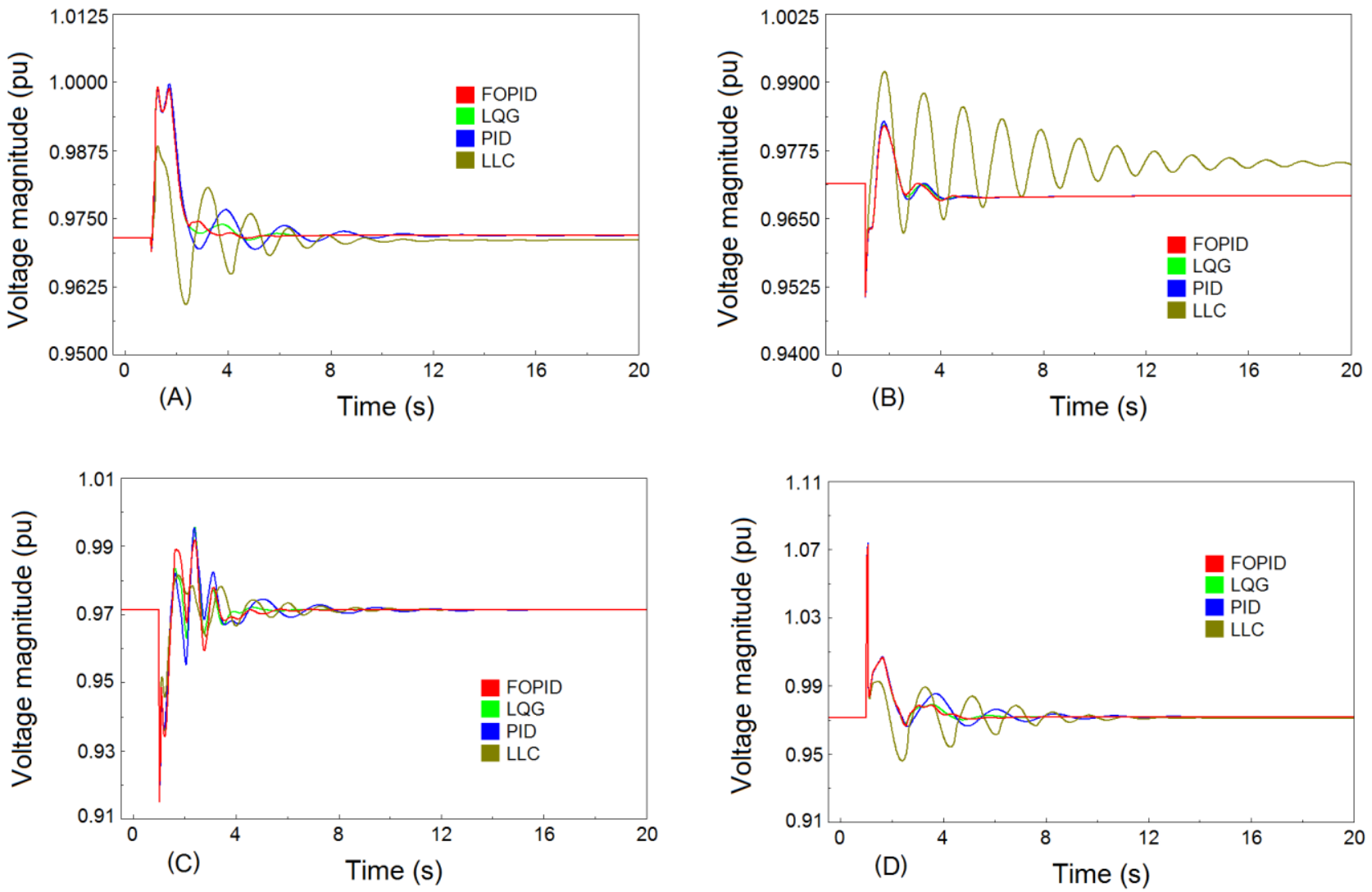

Figure 15. Voltage magnitude at bus 6 for scenario 2: (A) state 1, (B) state 2, (C) state 3, and (D) state 4.

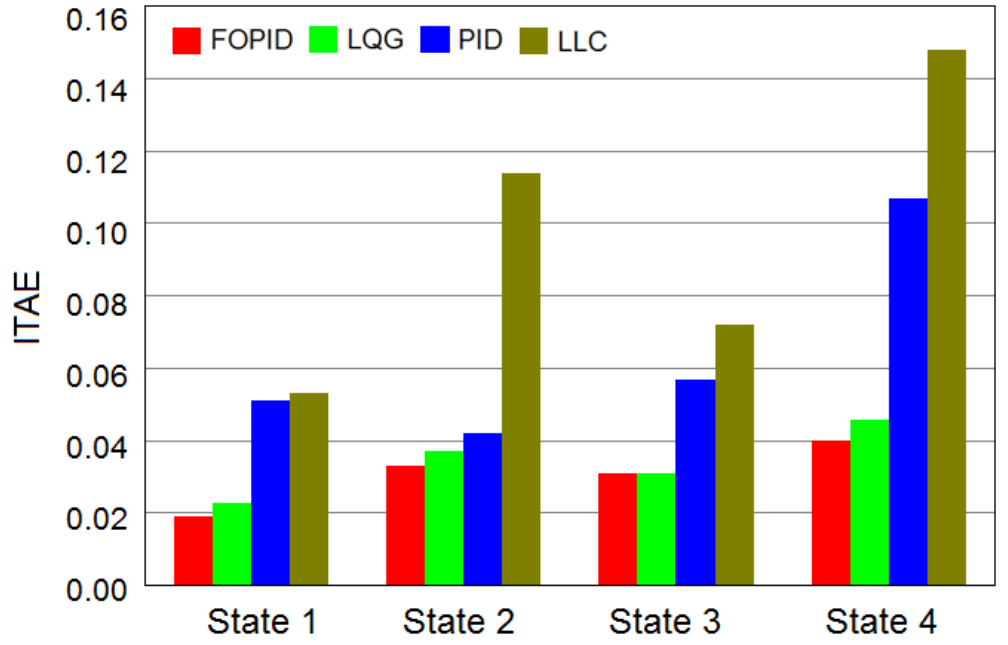

Figure 16. ITAE index for scenario 2.

\subsection{Scenario 3}

In this scenario, a 600 MVA LPF as an IBPP is connected to bus 6. In addition, the rating of generator $G_{2}$ has been changed from 900 MVA to 300 MVA. Furthermore, only generators G2 and G4 have the PSS. As shown in Figure 10, the LPF is equipped with a FOPID controller as a PODC. Based on Equations (21) and (22), the optimal values of the FOPID-PODC parameters are specified using the PSO algorithm, as listed in Table 9. In addition, the voltage control at plant level has been considered as the LPF control strategy [105-107]. Therefore, position 1 in Figure 9 is intended for the FOPID-PODC. So, bus 6 is considered as a PV bus [47]. For performance evaluation of the FOPID-PODC, 
this section compares the PODC performance with the literature, including LLCs [14,17], PID controllers [18], LQG controllers [11], and multiple-model adaptive control (MMAC) strategy [13]. The simulation results are shown in Figures 17 and 18. Moreover, the ITAE index is shown in Figure 19. The simulation results confirm the accuracy of the literature results.

Table 9. Optimal values of the FOPID-PODC parameters for scenario 3.

\begin{tabular}{ccc}
\hline Item & Value \\
\hline$K_{P}$ & 26.874 \\
$K_{I}$ & 32.821 \\
$K_{D}$ & 85.233 \\
$\lambda$ & 0.266 \\
$\delta$ & 0.219 \\
\hline
\end{tabular}
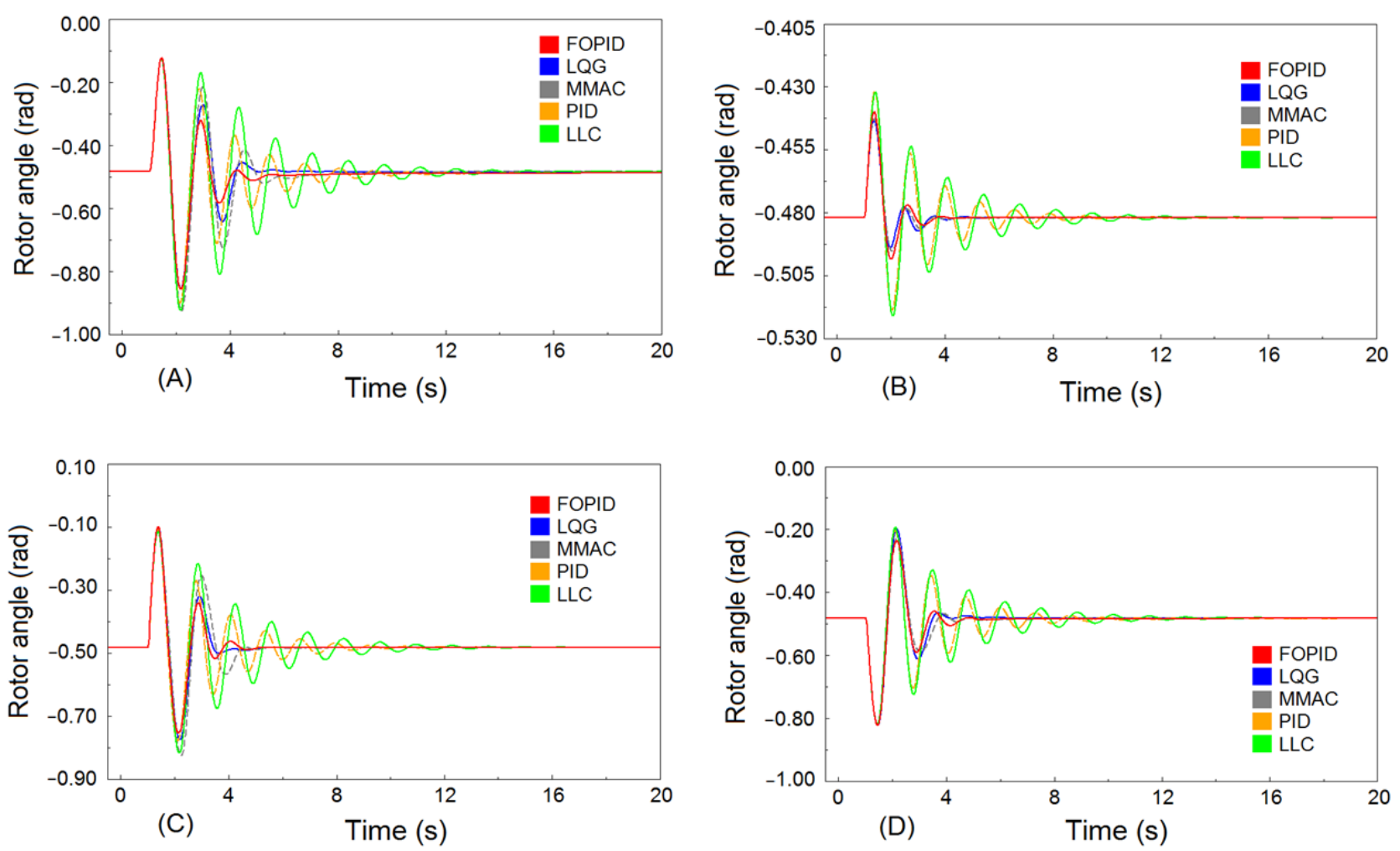

Figure 17. Rotor angle of generator G1 for scenario 3: (A) state 1, (B) state 2, (C) state 3, and (D) state 4.

It should be noted that the lower value of the ITAE index is due to the increase in the damping ratio, the decrease in the settling time as well as the decrease in the overshoot of the system response using the FOPID controller. Each of these three factors alone or together can change the ITAE index and affect the system response.

The simulation results show that the application of FOPID controllers has a great effect on reducing the risk of LFOs and increasing the power system stability. However, the use of this type of controller to mitigate the LFOs has not yet been applied or is very limited. The main reason is the obstacles and challenges that exist to expanding its applications. 

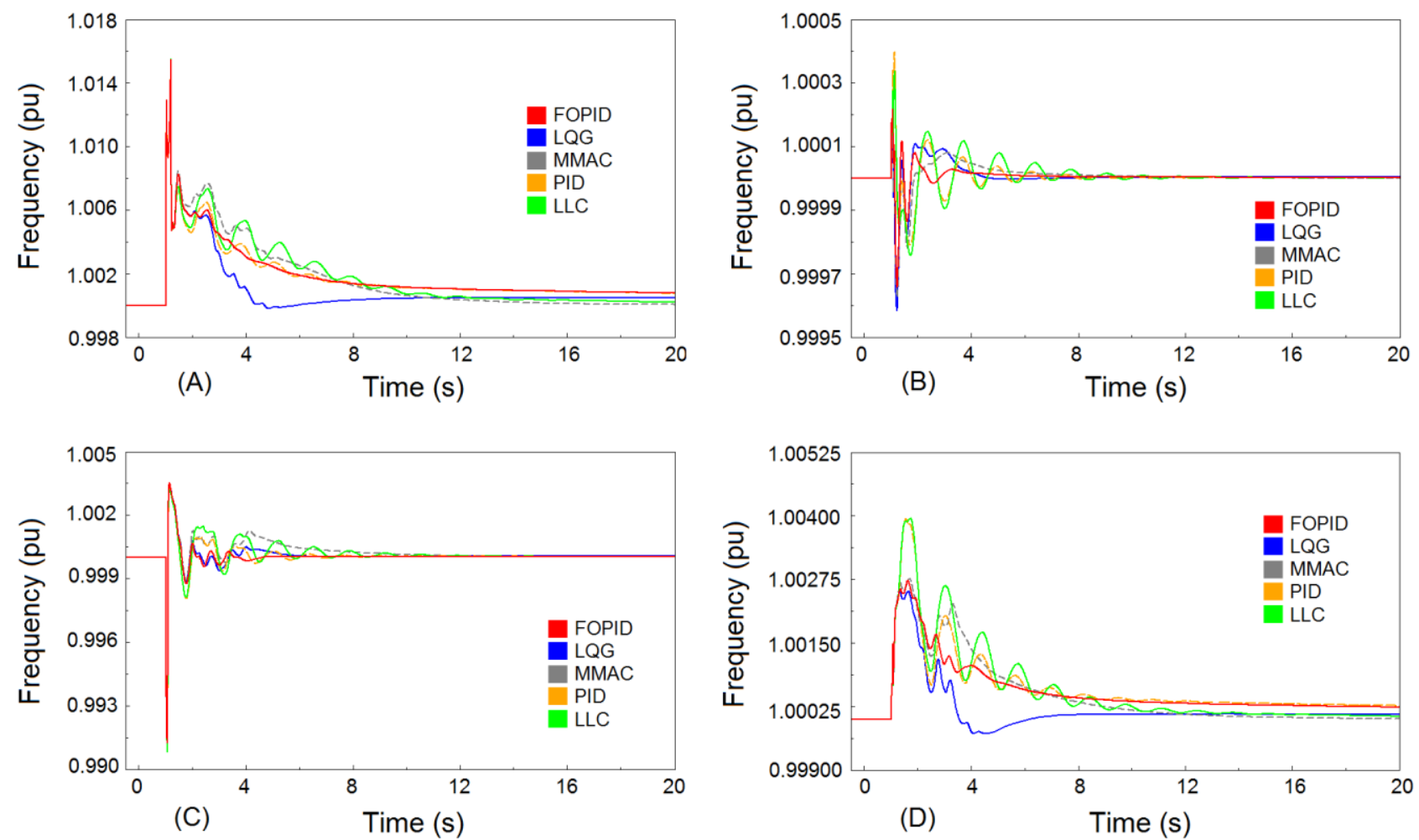

Figure 18. Power system frequency at bus 6 for scenario 3: (A) state 1, (B) state 2, (C) state 3, and (D) state 4.

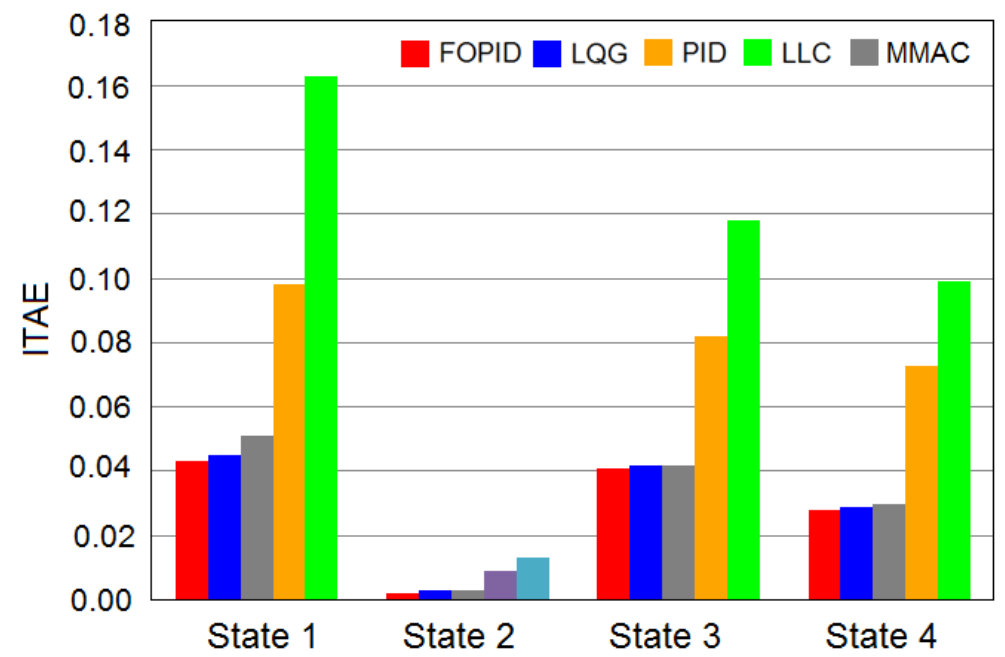

Figure 19. ITAE index for scenario 3.

\section{Opportunities and Challenges}

Power systems are moving to modern power systems to overcome environmental problems and fossil fuel shortages. Next-generation systems have a high penetration level of renewable energy power plants, most of which are IBPPs. Therefore, the high penetration level of IBPP greatly reduces the power system inertia, which affects the stability. On the other hand, due to the nature of renewable energy power plants, their production has high uncertainty and fluctuates. Such fluctuations lead to an increase in LFOs, which is one of the main problems in power systems. A common method for LFO damping is to use an auxiliary controller as a PODC. Today, the focus of research is on the main topics:

1. Using robust controllers with a higher range of stability area in accordance with the requirements of next-generation systems; 
2. Damping the LFOs using new devices in power systems, such as IBPPs and FACTS devices.

In recent years, the FOPID controller has been proposed as a PODC for LFO mitigation. The results of studies show that the FOPID-PODC performs better than conventional PODCs. The most important opportunities and benefits of using FOPID controllers in the power systems for LFO damping are listed in Table 10.

Table 10. Opportunities and benefits of the FOPID controller for LFO mitigation in power systems.

\begin{tabular}{cc}
\hline Opportunity & Description \\
\hline $\begin{array}{c}\text { Wide range of stability area } \\
\text { Robustness }\end{array}$ & $\begin{array}{r}\text { Due to the nature of the FOPID controller, this type of controller provides a large range of } \\
\text { stability area. }\end{array}$ \\
$\begin{array}{r}\text { Due to the natural properties of the FOPID controller, which is due to the fractional orders } \\
\text { of derivative and integral operators, this type of controller has a high robustness against } \\
\text { system uncertainties. }\end{array}$ \\
It seems that the most important opportunity created by fractional-order calculus is its \\
high flexibility to propose new types of robust PODCs in power systems by researchers.
\end{tabular}

However, there seem to be challenges and research gaps that need to be addressed in future studies. The main challenges and research gaps are addressed in Table 11.

Table 11. Research gaps and challenges of the FOPID controller for LFO mitigation in power systems.

Opportunity Description

Although FOPID controllers have better performance in terms of LFO damping than conventional controllers, their tuning is difficult and time consuming compared to

Auto-tuning conventional controllers. Given the need for auto-tuning in modern power systems and smart grids, this is one of the most fundamental challenges of these types of controllers. It seems that the industrial use of FOPID controllers can be developed by creating and developing auto-tuning techniques.

One of the major research gaps in this subject is the design of multi-band FOPID-PODCs. Multi-band PODCs have the ability to mitigate oscillations at different frequencies.

Multi-band FOPID-PODC

Commercialization and industrialization

Fractional-order-based software packages

Practical justification

Although, in recent years, some studies have designed PSS-based multi-band controllers [108-110] and fractional-order LLC-based multi-band controller [111], no study has been done on multi-band FOPID controllers.

One of the important research gaps of these types of controllers for PODC application in power systems is the examination of the capabilities for commercialization and industrialization. Conventional LLCs and PID controllers are easily and cheaply available for PODC applications. Today, conventional PSSs are based on LLCs that are very affordable and easy to design.

Given that the power system modeling in many software packages of electrical engineering is based on integer-order calculus, it is not possible to model the FOPID controllers. On the other hand, in many software packages where it is possible to model FOPID controllers, there is a limitation that the fractional orders cannot be variable. Therefore, it is impossible to tune the FOPID controller using these software packages. The most important challenge with fractional-order calculus is that there is currently no practical justification for a fractional-order integral or derivative, e.g., the integral of a function means the area under its curve, but there is still no practical justification for fractional-order integrals.

\section{Discussion}

The FOPID controllers have several technical advantages over integer-order controllers. However, for the industrial application of these types of controllers, it is necessary to overcome the limitations mentioned in Section 7. The use of FOPID controllers should be properly justified by superior performance or at least the same efficiency as the conventional PODCs. A Technology Readiness Level (TRL) may have to be established for an industry-implementation-ready FOPID controller $[112,113]$. Sometimes, the variation in 
FOPID controller parameters may result in instability, and hence the sensitivity of this type of controller to variations in the controller parameters should be studied.

As mentioned in Section 4, one of the main challenges of the FOPID controller is its tuning. The use of metaheuristic optimization techniques reduces the complexity of the design of fractional controllers. With the advances in artificial intelligence and fuzzy logic, better optimization methods can be used to tune the FOPID controllers. Such methods, with the inherent robustness of the FOPID controllers, can be used to obtain the desired system response.

The results obtained in Section 6 showed that the FOPID-PODC has a better performance than conventional PODCs in terms of LFO damping. Given that FOPID controllers are the extension form of the conventional PID controllers, which are the dominant controllers used by the industry, it can be expected that it will be easier to incorporate FOPID controllers soon into power systems.

\section{Conclusions}

In this paper, the applications of FOPID controllers in power systems for LFO damping were investigated. The most important feature of FOPID controllers that distinguishes them from other controllers is their wide stability range, which is due to the nature of these types of controllers. In this study, the difference between this type of controller and other controllers discussed in the literature in terms of mathematics was convincingly shown. Furthermore, the advantages of FOPID controllers were clearly identified in the simulations. The results of this review show that:

- Superior performance of the FOPID-PODC than conventional PODCs in terms of LFO mitigation;

- Superior performance of the FOPID-PODC than conventional PODCs in terms of robustness to some power system uncertainties.

This study also investigated the problems and challenges as well as opportunities in developing the applications of FOPID controllers. Although this type of controller has many advantages, considering the challenges mentioned, it has not been developed much in terms of application. Obviously, in the near future, with the development of mathematics and its applications in control engineering and industrialization of this type of controller, we can see the increasing development of FOPID controller applications in power systems to damp the LFOs.

Author Contributions: Conceptualization, M.S., and G.B.G.; methodology, M.S., G.B.G.; software, M.S.; validation, M.S., G.B.G., and I.K.; formal analysis, M.S., G.B.G., I.K., P.S., J.M.G. and H.H.A.; investigation, M.S., and G.B.G.; resources, M.S., G.B.G., and I.K.; data curation, M.S., G.B.G., and I.K.; writing—original draft preparation, M.S., G.B.G.; writing—review and editing, G.B.G., I.K., P.S., J.M.G., and H.H.A.; visualization, M.S.; supervision, G.B.G.; project administration, G.B.G.; funding acquisition, H.H.A., and P.S. All authors have read and agreed to the published version of the manuscript.

Funding: A part of this work has been funded by the Iran National Science Foundation (INSF) project No. 96005975 . The funding by INSF is greatly acknowledged by Gevork. B. Gharehpetian. Josep M. Guerrero was supported by VILLUM FONDEN under the VILLUM Investigator Grant (no. 25920): Center for Research on Microgrids (CROM); www.crom.et.aau.dk.

Institutional Review Board Statement: Not applicable.

Informed Consent Statement: Not applicable.

Data Availability Statement: Please have a contact with the authors.

Acknowledgments: A part of this work has been funded by the Iran National Science Foundation (INSF) project No. 96005975. The funding by INSF is greatly acknowledged by Gevork. B. Gharehpetian. Josep M. Guerrero was supported by VILLUM FONDEN under the VILLUM Investigator Grant (no. 25920): Center for Research on Microgrids (CROM); www.crom.et.aau.dk. 
Conflicts of Interest: The authors declare no conflict of interest.

\section{References}

1. Machowski, J.; Lubosny, Z.; Bialek, J.W.; Bumby, J.R. Power System Dynamics: Stability and Control; John Wiley \& Sons, Inc.: Hoboken, NJ, USA, 2020.

2. Kundur, P. Power System Stability and Control; McGraw-Hill: New York, NY, USA, 1994.

3. Pal, B.; Chaudhuri, B. Robust Control in Power Systems; Springer Science + Business Media, Inc.: Boston, MA, USA, 2010.

4. Rogers, G. Power System Oscillations; Kluwer Academic Publishers: Boston, MA, USA, 2000.

5. Shayeghi, H.; Safari, A.; Shayanfar, H. PSS and TCSC damping controller coordinated design using PSO in multi-machine power system. Energy Convers. Manag. 2010, 51, 2930-2937. [CrossRef]

6. Abido, M.A.; Abdel-Magid, Y.L. Coordinated design of a PSS and an SVC-based controller to enhance power system stability. Int. J. Electr. Power Energy Syst. 2003, 25, 695-704. [CrossRef]

7. Yao, W.; Jiang, L.; Wen, J.; Wu, Q.H.; Cheng, S. Wide-area damping controller of FACTS devices for inter-area oscillations considering communication time delays. IEEE Trans. Power Syst. 2013, 29, 318-329. [CrossRef]

8. Majumder, R.; Pal, B.C.; Dufour, C.; Korba, P. Design and real-time implementation of robust FACTS controller for damping inter-area oscillation. IEEE Trans. Power Syst. 2006, 21, 809-816. [CrossRef]

9. Hasanvand, H.; Arvan, M.R.; Mozafari, B.; Amraee, T. Coordinated design of PSS and TCSC to mitigate interarea oscillations. Int. J. Electr. Power Energy Syst. 2016, 78, 194-206. [CrossRef]

10. Salgotra, A.; Pan, S. A frequency domain model-based design of PSS and TCSC controller for damping the small signal oscillations in the power system. Int. Trans. Electr. Energy Syst. 2019, 29, e2742. [CrossRef]

11. Shah, R.; Mithulananthan, N.; Lee, K.Y. Large-scale PV plant with a robust controller considering power oscillation damping IEEE Trans. Energy Convers. 2012, 28, 106-116. [CrossRef]

12. Domínguez-García, J.L.; Gomis-Bellmunt, O.; Bianchi, F.D.; Sumper, A. Power oscillation damping supported by wind power: A review. Renew. Sustain. Energy Rev. 2012, 16, 4994-5006. [CrossRef]

13. Zhou, L.; Yu, X.; Li, B.; Zheng, C.; Liu, J.; Liu, Q.; Guo, K. Damping inter-area oscillations with large-scale PV plant by modified multiple-model adaptive control strategy. IEEE Trans. Sustain. Energy 2017, 8, 1629-1636. [CrossRef]

14. Singh, M.; Allen, A.J.; Muljadi, E.; Gevorgian, V.; Zhang, Y.; Santoso, S. Interarea oscillation damping controls for wind power plants. IEEE Trans. Sustain. Energy 2014, 6, 967-975. [CrossRef]

15. Varma, R.K.; Akbari, M. Simultaneous Fast Frequency Control and Power Oscillation Damping by Utilizing PV Solar System as PV-STATCOM. IEEE Trans. Sustain. Energy 2019, 11, 415-425. [CrossRef]

16. Gurung, S.; Jurado, F.; Naetiladdanon, S.; Sangswang, A. Optimized tuning of power oscillation damping controllers using probabilistic approach to enhance small-signal stability considering stochastic time delay. Electr. Eng. 2019, 101, 969-982. [CrossRef]

17. Varma, R.K.; Maleki, H. PV solar system control as STATCOM (PV-STATCOM) for power oscillation damping. IEEE Trans. Sustain. Energy 2018, 10, 1793-1803. [CrossRef]

18. Saadatmand, M.; Mozafari, B.; Gharehpetian, G.B.; Soleymani, S. Optimal PID controller of large-scale PV farms for power systems LFO damping. Int. Trans. Electr. Energy Syst. 2020, 30, e12372. [CrossRef]

19. Monje, C.A.; Chen, Y.; Vinagre, B.M.; Xue, D.; Feliu-Batlle, V. Fractional-Order Systems and Controls: Fundamentals and Applications; Springer: London, UK, 2010

20. Shah, P.; Agashe, S. Review of fractional PID controller. Mechatronics 2016, 38, 29-41. [CrossRef]

21. Podlubny, I. Fractional-order systems and $\mathrm{PI}^{\lambda} \mathrm{D}^{\mu}$-controllers. IEEE Trans. Autom. Control 1999, 44, 208-214. [CrossRef]

22. Chathoth, I.; Ramdas, S.K.; Krishnan, S.T. Fractional-order proportional-integral-derivative-based automatic generation control in deregulated power systems. Electr. Power Compon. Syst. 2015, 43, 1931-1945. [CrossRef]

23. Yohanandhan, R.V.; Srinivasan, L. Decentralised wide-area fractional order damping controller for a large-scale power system. IET Gener. Transm. Distrib. 2016, 10, 1164-1178. [CrossRef]

24. Ayres Junior, F.A.C.; Costa Junior, C.T.; de Medeiros, R.L.P.; Barra Junior, W.; das Neves, C.C.; Lenzi, M.K.; Veroneze, C.D.M. A Fractional Order Power System Stabilizer Applied on a Small-Scale Generation System. Energies 2018, 11, 2052. [CrossRef]

25. Tzounas, G.; Dassios, I.; Murad, M.A.; Milano, F. Theory and Implementation of Fractional Order Controllers for Power System Applications. IEEE Trans. Power Syst. 2020, 35, 4622-4631. [CrossRef]

26. Taher, S.A.; Fini, M.H.; Aliabadi, S.F. Fractional order PID controller design for LFC in electric power systems using imperialist competitive algorithm. Ain Shams Eng. J. 2014, 5, 121-135. [CrossRef]

27. Zamani, A.; Barakati, S.M.; Yousofi-Darmian, S. Design of a fractional order PID controller using GBMO algorithm for loadfrequency control with governor saturation consideration. ISA Trans. 2016, 64, 56-66. [CrossRef]

28. Saxena, S. Load frequency control strategy via fractional-order controller and reduced-order modeling. Int. J. Electr. Power Energy Syst. 2019, 104, 603-614. [CrossRef]

29. Mohamed, E.A.; Ahmed, E.M.; Elmelegi, A.; Aly, M.; Elbaksawi, O.; Mohamed, A.A. An Optimized Hybrid Fractional Order Controller for Frequency Regulation in Multi-Area Power Systems. IEEE Access 2020, 8, 213899-213915. [CrossRef]

30. Morsali, J.; Zare, K.; Hagh, M.T. A novel dynamic model and control approach for SSSC to contribute effectively in AGC of a deregulated power system. Int. J. Electr. Power Energy Syst. 2018, 95, 239-253. [CrossRef] 
31. Pan, I.; Das, S. Fractional order AGC for distributed energy resources using robust optimization. IEEE Trans. Smart Grid 2015, 7, 2175-2186. [CrossRef]

32. Gorripotu, T.S.; Samalla, H.; Rao, C.J.; Azar, A.T.; Pelusi, D. TLBO algorithm optimized fractional-order PID controller for AGC of interconnected power system. In Soft Computing in Data Analytics, Proceedings of the International Conference on SCDA 2018, Srikakulam, India, 10-11 March 2018.

33. Kumar, N.; Tyagi, B.; Kumar, V. Application of fractional order PID controller for AGC under deregulated environment. Int. J. Autom. Comput. 2018, 15, 84-93. [CrossRef]

34. Tasnin, W.; Saikia, L.C. Deregulated AGC of multi-area system incorporating dish-Stirling solar thermal and geothermal power plants using fractional order cascade controller. Int. J. Electr. Power Energy Syst. 2018, 101, 60-74. [CrossRef]

35. Mishra, A.K.; Das, S.R.; Ray, P.K.; Mallick, R.K.; Mohanty, A.; Mishra, D.K. PSO-GWO Optimized Fractional Order PID Based Hybrid Shunt Active Power Filter for Power Quality Improvements. IEEE Access 2020, 8, 74497-74512. [CrossRef]

36. Zamani, M.; Karimi-Ghartemani, M.; Sadati, N.; Parniani, M. Design of a fractional order PID controller for an AVR using particle swarm optimization. Control Eng. Pract. 2009, 17, 380-1387. [CrossRef]

37. Pan, I.; Das, S. Chaotic multi-objective optimization based design of fractional order PI $\mathrm{D} \mu$ controller in AVR system. Int. J. Electr. Power Energy Syst. 2012, 43, 393-407. [CrossRef]

38. Pan, I.; Das, S. Frequency domain design of fractional order PID controller for AVR system using chaotic multi-objective optimization. Int. J. Electr. Power Energy Syst. 2013, 51, 106-118. [CrossRef]

39. Chiranjeevi, S.B. Implementation of fractional order PID controller for an AVR system using GA and ACO optimization techniques. IFAC-PapersOnLine 2016, 49, 456-461.

40. Chaib, L.; Choucha, A.; Arif, S. Optimal design and tuning of novel fractional order PID power system stabilizer using a new metaheuristic Bat algorithm. Ain Shams Eng. J. 2017, 8, 113-125. [CrossRef]

41. Sikander, A.; Thakur, P.; Bansal, R.C.; Rajasekar, S. A novel technique to design cuckoo search based FOPID controller for AVR in power systems. Comput. Elec. Eng. 2018, 70, 261-274. [CrossRef]

42. Bhookya, J.; Jatoth, R.K. Optimal FOPID/PID controller parameters tuning for the AVR system based on sine-cosine-algorithm. Evol. Intell. 2019, 12, 725-733. [CrossRef]

43. Ray, P.K.; Paital, S.R.; Mohanty, A.; Foo, Y.E.; Krishnan, A.; Gooi, H.B.; Amaratunga, G.A. A hybrid firefly-swarm optimized fractional order interval type-2 fuzzy PID-PSS for transient stability improvement. IEEE Trans. Ind. App. 2019, 55, 6486-6498. [CrossRef]

44. Micev, M.; Ćalasan, M.; Oliva, D. Fractional order PID controller design for an AVR system using Chaotic Yellow Saddle Goatfish Algorithm. Mathematics 2020, 8, 1182. [CrossRef]

45. Morsali, J.; Zare, K.; Hagh, M.T. Applying fractional order PID to design TCSC-based damping controller in coordination with automatic generation control of interconnected multi-source power system. Eng. Sci. Technol. Int. J. 2017, 20, 1-7. [CrossRef]

46. Paital, S.R.; Ray, P.K.; Mohanty, A. Dolphin Echolocation and Fractional Order PID-Based STATCOM for Transient Stability Enhancement. In Recent Findings in Intelligent Computing Techniques, Proceedings of the 5th ICACNI, Goa, India, 1-3 June 2017; Springer: Singapore, 2018.

47. Saadatmand, M.; Mozafari, B.; Gharehpetian, G.B.; Soleymani, S. Optimal fractional-order PID controller of inverter-based power plants for power systems LFO damping. Turk. J. Electr. Eng. Comput. Sci. 2020, 28, 485-499. [CrossRef]

48. Saadatmand, M.; Mozafari, B.; Gharehpetian, G.B.; Soleymani, S. Optimal Coordinated Tuning of Power System Stabilizers and Wide-area Measurement-based Fractional-order PID Controller of Large-scale PV Farms for LFO Damping in Smart Grids. Int. Trans. Electr. Energy Syst. 2021, 31, e12612. [CrossRef]

49. Saadatmand, M.; Gharehpetian, G.B.; Siano, P.; Alhelou, H.H. PMU-based FOPID Controller of Large-scale Wind-PV Farms for LFO Damping in Smart Grid. IEEE Access 2021, 9, 94953-94969. [CrossRef]

50. Kundur, P.; Paserba, J.; Ajjarapu, V.; Andersson, G.; Bose, A.; Canizares, C.; Hatziargyriou, N.; Hill, D.; Stankovic, A.; Taylor, C.; et al. Definition and classification of power system stability IEEE/CIGRE joint task force on stability terms and definitions. IEEE Trans. Power Syst. 2004, 19, 1387-1401.

51. Hatziargyriou, N.; Milanovic, J.V.; Rahmann, C.; Ajjarapu, V.; Canizares, C.; Erlich, I.; Hill, D.; Hiskens, I.; Kamwa, I.; Pal, B.; et al. Definition and classification of power system stability revisited \& extended. IEEE Trans. Power Syst. 2020, 36, 3271-3281.

52. Hatziargyriou, N.; Milanovic, J.V.; Rahmann, C.; Ajjarapu, V.; Canizares, C.; Erlich, I.; Hill, D.; Hiskens, I.; Kamwa, I.; Pal, B.; et al. Stability Definitions and Characterization of Dynamic Behavior in Systems with High Penetration of Power Electronic Interfaced Technologies; Technical Report PESTR77; IEEE Power and Energy Society: Piscataway, NJ, USA, 2020.

53. Miller, K.S.; Ross, B. An Introduction to the Fractional Calculus and Fractional Differential Equations; John Wiley: New York, NY, USA, 1993.

54. Singh, H.; Kumar, D.; Baleanu, D. Methods of Mathematical Modelling: Fractional Differential Equations; CRC Press, Taylor \& Francis Group: Boca Raton, FL, USA, 2020.

55. Oldham, K.B.; Spanier, J. The Fractional Calculus; Academic Press: New York, NY, USA, 1974.

56. Lanusse, P.; Malti, R.; Melchior, P. CRONE control system design toolbox for the control engineering community: Tutorial and case study. Philos. Trans. R. Soc. A Math. Phys. Eng. Sci. 2013, 371, 20120149. [CrossRef]

57. Dastjerdi, A.A.; Saikumar, N.; HosseinNia, S.H. Tuning guidelines for fractional order PID controllers: Rules of thumb. Mechatronics 2018, 56, 26-36. [CrossRef] 
58. Sánchez, H.S.; Padula, F.; Visioli, A.; Vilanova, R. Tuning rules for robust FOPID controllers based on multi-objective optimization with FOPDT models. ISA Trans. 2017, 66, 344-361. [CrossRef] [PubMed]

59. Yousaf, S.; Mughees, A.; Khan, M.G.; Amin, A.A.; Adnan, M.A. A Comparative Analysis of Various Controller Techniques for Optimal Control of Smart Nano-Grid Using GA and PSO Algorithms. IEEE Access 2020, 8, 205696-205711. [CrossRef]

60. Daraz, A.; Malik, S.A.; Mokhlis, H.; Haq, I.U.; Zafar, F.; Mansor, N. N. Improved-Fitness Dependent Optimizer Based FOI-PD Controller for Automatic Generation Control of Multi-Source Interconnected Power System in Deregulated Environment. IEEE Access 2020, 8, 197757-197775. [CrossRef]

61. Wang, H.; Wang, H.; Zeng, G.; Dai, Y.; Bi, D.; Sun, J.; Xie, X. Design of a fractional order frequency PID controller for an islanded microgrid: A multi-objective extremal optimization method. Energies 2017, 10, 1502. [CrossRef]

62. Nie, Y.; Zhang, Y.; Zhao, Y.; Fang, B.; Zhang, L. Wide-area optimal damping control for power systems based on the ITAE criterion. Int. J. Electr. Power Energy Syst. 2019, 106, 192-200. [CrossRef]

63. Khezri, R.; Oshnoei, A.; Tarafdar Hagh, M.; Muyeen, S.M. Coordination of heat pumps, electric vehicles and AGC for efficient LFC in a smart hybrid power system via SCA-based optimized FOPID controllers. Energies 2018, 11, 420. [CrossRef]

64. Pan, I.; Das, S. Fractional-order load-frequency control of interconnected power systems using chaotic multi-objective optimization. Appl. Soft Comput. 2015, 29, 328-344. [CrossRef]

65. Irudayaraj, A.X.R.; Wahab, N.I.; Umamaheswari, M.G.; Radzi, M.A.; Sulaiman, N.B.; Veerasamy, V.; Prasanna, S.C.; Ramachandran, R. A Matignon's Theorem Based Stability Analysis of Hybrid Power System for Automatic Load Frequency Control Using Atom Search Optimized FOPID Controller. IEEE Access 2020, 8, 168751-168772. [CrossRef]

66. Hekimoğlu, B. Optimal Tuning of Fractional Order PID Controller for DC Motor Speed Control via Chaotic Atom Search Optimization Algorithm. IEEE Access 2019, 7, 38100-38114. [CrossRef]

67. Arya, Y.; Kumar, N. BFOA-scaled fractional order fuzzy PID controller applied to AGC of multi-area multi-source electric power generating systems. Swarm Evol. Comput. 2017, 32, 202-218. [CrossRef]

68. Morsali, J.; Zare, K.; Hagh, M.T. Modified group search optimisation-based comparative performance evaluation of thyristor controlled series capacitor-based fractional order damping controllers to improve load frequency control performance in restructured environment. IET Gener. Transm. Distrib. 2017, 11, 4654-4669. [CrossRef]

69. Ismayil, C.; Kumar, R.S.; Sindhu, T.K. Optimal fractional order PID controller for automatic generation control of two-area power systems. Int. Trans. Electr. Energy Syst. 2015, 25, 3329-3348. [CrossRef]

70. Zhao, P.; Malik, O.P. Design of an adaptive PSS based on recurrent adaptive control theory. IEEE Trans. Energy Convers. 2009, 24, 884-892. [CrossRef]

71. Zhang, S.; Luo, F.L. An improved simple adaptive control applied to power system stabilizer. IEEE Trans. Power Electron. 2009, 24, 369-375. [CrossRef]

72. Milla, F.; Duarte-Mermoud, M.A. Predictive optimized adaptive PSS in a single machine infinite bus. ISA Trans. 2016, 63, 315-327. [CrossRef]

73. Barreiros, J.A.; Ferreira, A.M.; Tavares-da-Costa, C., Jr.; Barra, W., Jr.; Lopes, J.A. A neural power system stabilizer trained using local linear controllers in a gain-scheduling scheme. Int. J. Electr. Power Energy Syst. 2005, 27, 473-479. [CrossRef]

74. Hasanovic, A.M.; Feliachi, A.; Bhatt, N.B.; DeGroff, A.G. Practical robust PSS design through identification of low-order transfer functions. IEEE Trans. Power Syst. 2004, 19, 1492-1500. [CrossRef]

75. Bandal, V.; Bandyopadhyay, B. Robust decentralised output feedback sliding mode control technique-based power system stabiliser (PSS) for multimachine power system. IET Control Theory Appl. 2007, 1, 1512-1522. [CrossRef]

76. Bakhshi, M.; Holakooie, M.H.; Rabiee, A. Fuzzy based damping controller for TCSC using local measurements to enhance transient stability of power systems. Int. J. Electr. Power Energy Syst. 2017, 85, 12-21. [CrossRef]

77. Kalyan, C.N.; Rao, G.S. Coordinated SMES and TCSC Damping Controller for Load Frequency Control of Multi Area Power System with Diverse Sources. Int. J. Electr. Eng. Inform. 2020, 12, 747-769.

78. Luburić, Z.; Pandžić, H.; Carrión, M. Transmission Expansion Planning Model Considering Battery Energy Storage, TCSC and Lines Using AC OPF. IEEE Access 2020, 8, 203429-203439. [CrossRef]

79. Ordóñez, C.A.; Gómez-Expósito, A.; Maza-Ortega, J.M. Series Compensation of Transmission Systems: A Literature Survey. Energies 2021, 14, 1717. [CrossRef]

80. Eftekharnejad, S.; Vittal, V.; Heydt, G.T.; Keel, B.; Loehr, J. Impact of increased penetration of photovoltaic generation on power systems. IEEE Trans. Power Syst. 2012, 28, 893-901. [CrossRef]

81. Quintero, J.; Vittal, V.; Heydt, G.T.; Zhang, H. The impact of increased penetration of converter control-based generators on power system modes of oscillation. IEEE Trans. Power Syst. 2014, 29, 2248-2256. [CrossRef]

82. Pourbeik, P.; Sanchez-Gasca, J.J.; Senthil, J.; Weber, J.D.; Zadehkhost, P.S.; Kazachkov, Y.; Tacke, S.; Wen, J.; Ellis, A. Generic dynamic models for modeling wind power plants and other renewable technologies in large-scale power system studies. IEEE Trans. Energy Convers. 2016, 32, 1108-1116. [CrossRef]

83. Canizares, C.; Fernandes, T.; Geraldi, E.; Gerin-Lajoie, L.; Gibbard, M.; Hiskens, I.; Kersulis, J.; Kuiava, R.; Lima, L.; DeMarco, F.; et al. Benchmark Models for the Analysis and Control of Small-Signal Oscillatory Dynamics in Power Systems. IEEE Trans. Power Syst. 2017, 32, 715-722. [CrossRef]

84. Cai, D. Wide Area Monitoring, Protection and Control in the Future Great Britain Power System. Ph.D. Thesis, University of Manchester, Manchester, UK, 2012. 
85. Kerahroudi, S.K.; Alamuti, M.M.; Li, F.; Taylor, G.A.; Bradley, M.E. Application and Requirement of DIgSILENT PowerFactory to MATLAB/Simulink Interface. In PowerFactory Applications for Power System Analysis; Gonzalez-Longatt, F.M., Rueda, J.L., Eds.; Springer: Cham, Switzerland, 2014; pp. 297-322.

86. Das, T.K.; Venayagamoorthy, G.K.; Aliyu, U.O. Bio-inspired algorithms for the design of multiple optimal power system stabilizers: SPPSO and BFA. IEEE Trans. Ind. Appl. 2008, 44, 1445-1457. [CrossRef]

87. Li, C.; Deng, J.; Zhang, X.P. Coordinated design and application of robust damping controllers for shunt FACTS devices to enhance small-signal stability of large-scale power systems. CSEE J. Power Energy Syst. 2017, 25, 399-407. [CrossRef]

88. Yathisha, L.; Patilkulkarni, S. LQR and LQG based optimal switching techniques for PSS and UPFC in power systems. Control Theory Technol. 2018, 16, 25-37. [CrossRef]

89. Ghouraf, D.E.; Naceri, A. Robust $\mathrm{H}_{2}$-PSS design based on LQG control optimized by genetic algorithms. Autom. Control Comput. Sci. 2017, 51, 301-310. [CrossRef]

90. ASV, V.L.; Manyala, R.R.; Mangipudi, S.K. Design of a robust PID-PSS for an uncertain power system with simplified stability conditions. Prot. Control Mod. Power Syst. 2020, 5, 20.

91. Dudgeon, G.J.W.; Leithead, W.E.; Dysko, A.; o'Reilly, J.; McDonald, J.R. The Effective Role of AVR and PSS in Power Systems: Frequency Response Analysis. IEEE Trans. Power Syst. 2007, 22, 1986-1994. [CrossRef]

92. Chatterjee, A.; Mukherjee, V.; Ghoshal, S.P. Velocity relaxed and craziness-based swarm optimized intelligent PID and PSS controlled AVR system. Int. J. Electr. Power Energy Syst. 2009, 31, 323-333. [CrossRef]

93. Mukherjee, V.; Ghoshal, S.P. Comparison of intelligent fuzzy based AGC coordinated PID controlled and PSS controlled AVR system. Int. J. Electr. Power Energy Syst. 2007, 29, 679-689. [CrossRef]

94. Ramos, R.A. Stability analysis of power systems considering AVR and PSS output limiters. Int. J. Electr. Power Energy Syst. 2009, 31, 153-159. [CrossRef]

95. Dysko, A.; Leithead, W.E.; O’Reilly, J. Enhanced Power System Stability by Coordinated PSS Design. IEEE Trans. Power Syst. 2010, 25, 413-422. [CrossRef]

96. Prasertwong, K.; Mithulananthan, N.; Thakur, D. Understanding low-frequency oscillation in power systems. Int. J. Electr. Eng. Educ. 2010, 47, 248-262.

97. Liu, H.; Su, J.; Yang, Y.; Qin, Z.; Li, C. Compatible Decentralized Control of AVR and PSS for Improving Power System Stability. IEEE Syst. J. 2020, 15, 2410-2419. [CrossRef]

98. Kumar, A. Ideal AVR and PSS: A theoretical study. IET Gener. Transm. Distrib. 2020, 14, 6250-6258. [CrossRef]

99. Son, K.M.; Park, J.K. On the robust LQG control of TCSC for damping power system oscillations. IEEE Trans. Power Syst. 2000, 15, 1306-1312. [CrossRef]

100. Ferreira, A.M.; Barreiros, J.A.; Barra, J.R.W.; Brito-de-Souza, J.R. A robust adaptive LQG/LTR TCSC controller applied to damp power system oscillations. Electr. Power Syst. Res. 2007, 77, 956-964. [CrossRef]

101. Zolotas, A.C.; Chaudhuri, B.; Jaimoukha, I.M.; Korba, P. A Study on LQG/LTR Control for Damping Inter-Area Oscillations in Power Systems. IEEE Trans. Control Syst. Technol. 2007, 15, 151-160. [CrossRef]

102. Panda, S. Differential evolutionary algorithm for TCSC-based controller design. Simul. Model. Pract. Theory 2009, 17, 1618-1634. [CrossRef]

103. Fan, L.; Feliachi, A.; Schoder, K. Selection and design of a TCSC control signal in damping power system inter-area oscillations for multiple operating conditions. Electr. Power Syst. Res. 2002, 62, 127-137. [CrossRef]

104. Abdel-Magid, Y.L.; Abido, M.A. Robust coordinated design of excitation and TCSC-based stabilizers using genetic algorithms. Electr. Power Syst. Res. 2004, 69, 129-141. [CrossRef]

105. WECC. PV Plant Power Flow Modeling Guide; Western Electricity Coordinating Council: Salt Lake City, UT, USA, 2010.

106. WECC. Renewable Energy Modeling Task Force: WECC PV Power Plant Dynamic Modeling Guide; Western Electricity Coordinating Council: Salt Lake City, UT, USA, 2014.

107. Pourbeik, P. Model User Guide for Generic Renewable Energy System Models; Electric Power Research Institute: Palo Alto, CA, USA, 2015.

108. Kamwa, I.; Grondin, R.; Trudel, G. IEEE PSS2B versus PSS4B: The limits of performance of modern power system stabilizers. IEEE Trans. Power Syst. 2005, 20, 903-915. [CrossRef]

109. Khodabakhshian, A.; Hemmati, R.; Moazzami, M.M. Multi-band power system stabilizer design by using CPCE algorithm for multi-machine power system. Electr. Power Syst. Res. 2013, 101, 36-48. [CrossRef]

110. Rimorov, D.; Kamwa, I.; Joós, G. Model-based tuning approach for multi-band power system stabilisers PSS4B using an improved modal performance index. IET Gener. Transm. Distrib. 2015, 9, 2135-2143. [CrossRef]

111. Abdulkhader, H.K.; Jacob, J.; Mathew, A.T. Fractional-order lead-lag compensator-based multi-band power system stabiliser design using a hybrid dynamic GA-PSO algorithm. IET Gener. Transm. Distrib. 2018, 12, 3248-3260. [CrossRef]

112. Warrier, P.; Shah, P. Fractional Order Control of Power Electronic Converters in Industrial Drives and Renewable Energy Systems: A Review. IEEE Access 2021, 9, 58982-59009. [CrossRef]

113. Tepljakov, A.; Alagoz, B.B.; Yeroglu, C.; Gonzalez, E.A.; Hosseinnia, S.H.; Petlenkov, E.; Ates, A.; Cech, M. Towards Industrialization of FOPID Controllers: A Survey on Milestones of Fractional-Order Control and Pathways for Future Developments. IEEE Access 2021, 9, 21016-21042. [CrossRef] 